\title{
Inspection-while-flying: An Autonomous Contact-based Nondestructive Test Using UAV-tools
}

\author{
Basaran Bahadir Kocer ${ }^{\mathrm{a}, \mathrm{b}}$, Tegoeh Tjahjowidodo ${ }^{\mathrm{a}}$, Mahardhika Pratama ${ }^{\mathrm{c}}$, Gerald Gim Lee Seet ${ }^{\mathrm{a}}$ \\ ${ }^{a}$ School of Mechanical and Aerospace Engineering, Nanyang Technological University, Singapore \\ ${ }^{b}$ Energy Research Institute @ NTU, Nanyang Technological University, Singapore \\ ${ }^{c}$ School of Computer Science and Engineering, Nanyang Technological University, Singapore
}

\begin{abstract}
Today's modern cities depend on basic services such as water and sewer systems including tunnels, which are supported by a pervasive infrastructure. The structural condition of these places is naturally prone to deterioration. Therefore, regular inspections are required for early detection of damage and material failure. It is envisaged that robotic systems may provide an up-to-date solution for this inspection task. Considering the challenging conditions in the surrounding environments, unmanned aerial vehicles (UAVs) may be a potential candidate to meet the need for both purely visual (contactless) and subsurface (contact-based) inspection functionalities. When the interaction with an uncooperative target is required, the UAV needs to be aware of the forces arising during the contact phase. This stage brings additional challenges including a variable center of gravity as well as the moment of inertias due to the shift in the attached parts, sliding on the target because of the surface characteristics and reaching desired interaction levels out of the equilibrium point without crashing the dedicated sensors while creating counter forces (reactions) in a desired manner. At the same time, ultrasonic inspection requires uninterrupted contact in certain force ranges. In order to address these factors in a compact and feasible manner, an optimization algorithm consisting of nonlinear moving horizon estimation (NMHE), which is a part of nonlinear model predictive control (NMPC) is proposed. In this algorithm, the baseline model of the UAV is augmented by the external forces where uncertainties, modeling mismatches and disturbances are lumped. Therefore, the NMHE has estimated these values in an online manner. In a simultaneous fashion, the identified external forces are fed into the NMPC to physically interact with the ceiling during the contact phase. The experimental inspection data is collected while autonomously staying in predefined constraint limits. It is observed that the complete inspection data is obtained and streamed via Bluetooth when the force on the ultrasonic tool reached $5.5 \mathrm{~N}$ level. The external force update coming from the estimation allows the proposed approach to reach these interaction levels.
\end{abstract}

Keywords: unmanned aerial vehicles, physical interaction, aerial contact, nondestructive test, moving horizon estimation, model predictive control, quadrotor, interaction control

\section{Introduction}

The civil infrastructure systems are the core parts of modern cities. The safe operation and maintenance of these systems are required to have complete and accurate information about

5 the existing conditions. Amongst these infrastructure systems, ${ }_{25}$ the surroundings (e.g., pipelines and tunnels) might be exposed to heavy burdens (e.g., a landslide on top of the surrounding), variable pressures, dense humid and various chemicals. The structural condition of these places deteriorates in time due to

10 the internal and external effects (e.g., aging of the material) [1] $]_{30}$ This necessitates the system to be kept under repetitive tests and preventive actions. It is vital to protect our infrastructure systems but we still have witnessed catastrophic crashes as a consequence of the lack of efficient maintenance. One of the 15 examples is the Sasago Tunnel, which was ended up with a catastrophic collapse [2]. Currently, in most countries; water supply, railways, and roads must be designed in space efficient ${ }^{35}$ manner while keeping the safety at the top level [3, 4]. Several unfortunate incidents show that even with advanced engineering
20 applied to the Sasago Tunnel, the collapse occurred in 2012. A similar incident is reported in [5], for a big ceiling collapse in 2006, which took place in Boston. Considering the compact city configuration and transportation in Singapore, where the deep tunnel sewerage system comprises a $48 \mathrm{~km}$ long deep sewer tunnel, its inspections deserve a high level of attention. From the illustrated fatal incidents mentioned above, it is concluded that there is an urgent need for unmanned, fully and/or semiautomated, as well as cost effective tunnel inspection strategies to prevent such catastrophic disasters not only in Singapore but whole around the world.

\subsection{Motivation}

It is clear that the structural abnormalities of the surrounding environment could lead to inevitable disasters. Therefore, it is vital to consider preventative maintenance by repetitive actions with observations and inspection operations. As a result of the detrimental effects, the most common deficiencies for two common structures are described in the manual for the tunnel operations [6]. In concrete structures; scaling, cracking, delam- 


\begin{tabular}{|c|c|c|c|}
\hline \multicolumn{4}{|c|}{ Nomenclature } \\
\hline$(\cdot)^{\mathrm{T}}$ & Vector or matrix transpose & $I_{\star \star}$ & Moments of inertias about $x, y$ and $z$ \\
\hline$\Delta z$ & Change of the UAV's tool length & $L, M, N$ & $\begin{array}{l}\text { Roll, pitch and yaw moments; their variant with } \star_{\text {ext }} \\
\text { represent external torques }\end{array}$ \\
\hline $\mathbf{0}_{\text {nxm }}$ & $(n \times m)$ matrix whose elements are zeros & $l_{\mathrm{s}}$ & UAV tool length \\
\hline $\mathbf{I}_{n}$ & 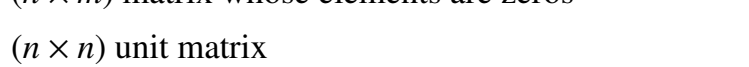 & $p, q, r$ & Roll, pitch and yaw rates \\
\hline $\mathcal{F}_{\star}$ & $\begin{array}{l}\text { Axes frames, subscripts C and B are intermediate } \\
\text { frames }\end{array}$ & $\begin{array}{l}R_{\mathrm{r}} \\
s, c, \mathrm{t}\end{array}$ & $\begin{array}{l}\text { Euler rotation matrix } \\
\text { Sine }(\sin ), \text { cosine }(\cos ) \text { and tangent }(\text { tan })\end{array}$ \\
\hline $\mathrm{h}(\cdot)$ & $\begin{array}{l}\text { Measurement function } \\
\text { Parameter vector }\end{array}$ & $t_{\star}$ & $\begin{array}{l}\text { Time, subscripts } k, E W, h \text { and } f \text { indicate any time } \\
\text { instant, estimation window, prediction horizon and } \\
\text { total flight time respectively }\end{array}$ \\
\hline $\mathrm{u}$ & $\begin{array}{l}\text { Input vector, its variant with subscript } n \text { indicates } \\
\text { nominal input vector }\end{array}$ & $u, v, w$ & Translational velocities \\
\hline $\mathrm{x}$ & $\begin{array}{l}\text { State vector, its variant with subscript } r \text { indicates } \\
\text { reference state vector }\end{array}$ & $x, y, z$ & $\begin{array}{l}\text { Translational positions with respect to the transla- } \\
\text { tional axes } \mathbf{x}_{\star}, \mathbf{y}_{\star}, \mathbf{z}_{\star}\end{array}$ \\
\hline $\mathrm{y}_{m}$ & Measurement vector & $\mathbb{R}^{n \times m}$ & Real-valued $n \times m$ matrices \\
\hline$\|V\|_{\mathrm{Q}}^{2}$ & $\begin{array}{l}\text { Weighted } \ell_{2} \text { norm: } V^{\mathrm{T}} \mathrm{Q} V \text {, for a } V \text { in the size of }(n \times \\
\text { 1) }\end{array}$ & $F_{\star, \mathrm{ext}}$ & $\begin{array}{l}\text { External forces acting on the rigid body about } x, y \\
\text { and } z\end{array}$ \\
\hline$\Omega_{i}$ & Rotor velocity & ACADO & Outomatic Control and Dynamic Optimization \\
\hline$\phi, \theta, \psi$ & Roll, pitch and yaw angles & blkdiag( & $\begin{array}{l}\left(V_{1}, V_{2}, \ldots, V_{n}\right) \text { Block diagonal concatenation of ma- } \\
\text { trices } V_{1}, \ldots, V_{n}\end{array}$ \\
\hline $\mathrm{c}_{\mathrm{T}}, \mathrm{c}_{\mathrm{D}}$ & Thrust and drag coefficient of the propeller & DoF & Degree of freedom \\
\hline$c_{v}$ & Sound velocity constant of the material & KKT & Karush-Kuhn-Tucker \\
\hline $\mathrm{H}, \mathrm{P}$ & NMHE covariance matrices & LQR & Linear quadratic regulator \\
\hline 1 & UAV mase and the oravity & $\max$ & Maximum \\
\hline O.R.S & NMPC weight matrices & MIMO & Multi-input-multi-output \\
\hline & Nivirc wergnt matrices & $\min$ & Minimum \\
\hline $\mathbf{1}_{\mathrm{m}}$ & Inickness or the material & NMHE & Nonlinear moving horizon estimation \\
\hline & Iransiormation matrix Irom $F_{\Delta}$ to $F_{\star}$ & NMPC & Nonlinear model predictive control \\
\hline & frame and B-body frame & PID & Proportional integral derivative \\
\hline$a, e, K$ & A system constant, error state and feedback controller & QP & Quadratic programming \\
\hline & gain & RTI & Real time iteration \\
\hline$f_{i}, \tau_{i}$ & Force and moment generated by each rotor & SQP & Sequential quadratic programming \\
\hline$F_{z}$ & Vertical force generated by rotors & UAV & Unmanned aerial vehicle \\
\hline
\end{tabular}

ination, spalling, pop-outs, mud balls, efflorescence, staining, 50 40 honeycombing, and leakages are the main defects. While in steel structures; corrosion, cracks, buckles, and kinks are the main deformations. To identify these defects, nondestructive methods have to be implemented. As it is still common, the inspection can be conducted by formal experts, but it may not be possible 55 45 to reach all parts of the surrounding environment. In addition, the operators may need to work under harsh conditions and their evaluations may be subjective. Motivated by the aforementioned factors, automated inspection operations by robots may be a de facto way to conduct, evaluate and post-process the tests in near ${ }_{60}$ future [7]. In these systems, the robotic arm might be equipped with an ultrasonic sensor to check the integrity of the concrete structure of the tunnel [8]. It is also worth to note that the places to be inspected could be in the absence of proper lighting. In this context, the remote inspection by the camera may not be adequate to detect leakages and integrity of the concrete structure, which is the reason why there are numerous contact-based sensors as given in [9, 10] and [11]. Although significant developments have taken place in the robotic systems [12], the operation workplace stands as a bottleneck, e.g., tight spaces or very high ceilings. Current and future robotic inspection studies 
$\&$ projects may require operation flexibility in both large and limited spaces. Hence, an endowed UAV with dedicated sensors (contactless and/or contact-based) can guarantee the wider range operability [13]: (i) specified rotor configuration of UAV $\mathrm{S}_{120}$ 65 enables flight through tight spaces; (ii) the achievable scale of the rotor-based aerial vehicles allows us to reach the confined spaces; (iii) the use of the symmetrically and vertically placed propellers provides UAVs to hover in the air - this particular feature enables us to use UAVs as active objects, such as inspection ${ }_{125}$ operation by contact; (iv) the rotor-based aerial vehicles can fly aggressively as compared to the fixed wing aerial vehicles. In addition, the ability to vertically take-off and land eliminates the necessity for specific paths and makes possible to take-off and land on both flat and harsh surfaces [14].

\section{1.2. Literature Review}

By providing the "first person view" feature, the use of UAVs within flying camera concept was and still is a popular application [15, 16, 17]. For instance, in [18], the images below ${ }_{135}$ the tunnel are collected for post-processing. Unfortunately, the system is controlled manually, which may not be precise for hard-to-reach places. Similarly, a crack detection investigation of the steel and concrete structures is considered in [19, 20] with a manual flight. The precise control below the ceiling is not discussed in these implementations. Furthermore, recent ${ }_{140}$ applications also explore the aerial photography for the crack [21, 22, 23] and delamination/corrosion [24, 25] inspection as well as thermal images [26], these also require a stationary keeping in the air which can be troublesome when a proper control approach is not utilized.

The expectation of UAVs has shifted to another level, wherein the flying system interacts with its environment, people and other robots in order to contribute decision-making process [27, 28, 29]. In this context, one of their use in the transportation of concrete beams is investigated in [30]. Furthermore, $\mathrm{a}_{150}$ foam material is extruded in [31] for a repair task. In a general perspective, readers interested in the use of UAVs in an active physical interaction manner can refer to recent review and survey papers: [32, 33, 34]. There are also recent attempts including inspection while the UAV engages with an interaction ${ }_{155}$ task instead of pure free-flight [35, 36, 37]. Among these, a two degree of freedom manipulator to check the integrity of the weld using eddy current is presented in [38]. In this implementation, PD-based controller is used, which may not capture the system behavior in higher force interaction ranges. Additionally, in ${ }_{160}$ studies, the tool is attached below the UAV, which may not be suitable for the ceiling-like structures. One of the initial implementations considering ceiling contact is [39], where the system locks itself to the ceiling. In this implementation, the discussion on the contact forces and the inspection are not ${ }_{165}$ presented. A similar implementation to hang the UAV at some anchor points is presented in [40, 41, 42]. In order to inspect the ceiling, a PID control scheme is considered in [43] for a robotic arm attached on the UAV. Furthermore, a backstepping approach is also evaluated in [44]. In these studies, the inspection aspects 170 15 are not discussed. Instead, a mockup sensor is tested to observe the control performance. Moreover, the contact force values are not further analyzed, where the system may not reach high interaction ranges considering pure PID and/or backstepping approaches. In an inspection context, an ultrasonic sensor is added on a tricopter for vertical wall contact in [45] without discussing control aspects which is crucial for an in-situ inspection. Recently, a hammer test is proposed in [46] for the horizontal and vertical walls. In this implementation, a one DoF manipulator is added on UAV and the overall system is controlled by PID. This study is extended in [47] for the bridge piers and floor stabs with a three DoF manipulator. Unfortunately, PID does respect the constraints neither on the control actions nor on the states; the sensor and/or tool might end up with a crash as a result of an extreme reaction during the contact phase. In addition, the additional payloads for this particular inspection operation require the system to be bigger (its weight is $16.8 \mathrm{~kg}$ and the width is $180 \mathrm{~cm}$ ), which may lose the advantage of operating in narrow openings. A typical tunnel opening in Singapore can be seen in the Appendix, which is in the size of $60 \times 60 \mathrm{~cm}$. A recent attempt utilizes an omnidirectional tool for the inspection operation [48], without considering aerodynamic forces which can be troublesome in a close proximity flight to the ceiling.

\subsection{Contribution}

The following bottlenecks are noted in the current applications: (i) most of the implementations consider the tool from the underside of the UAV; (ii) most of the applications use mock-up sensors instead of real inspection sensors; (iii) the constraint satisfaction has received less attention. The main idea behind the constraint satisfaction is to enable the system which operates in the largest safe region. Currently, there are some approaches that consider the physical limits within the controller, which is based on imposing physical actuator limitations to the output of the controller actions. However, the safe region could be smaller than predefined limits during the operation. Moreover, output or state constraints may impose an additional desirable region. Being different from conventional approaches, NMPC does not just limit its actuator but this approach stands out as a method that considers physical and environmental limitations of the system during the optimal solution search. This property of NMPC approach becomes more valuable when a nonlinear system is considered where constraints can influence the optimal solution substantially. It also diverges from other tools by mature solving methods when state of art quadratic programming (QP) solvers are considered. In this study, different from the current optimization-based approaches [49, 50, 51], the centralized baseline model of the UAV is augmented considering external forces. In [49], the system is decomposed into multiple models without considering external forces. Similarly, nominal models are utilized in [50, 51] and the external forces are not considered. In our proposed approach; the uncertainties, mismatches, and disturbances are lumped to these external forces as additive terms. Therefore, a constraint optimization-based estimator called NMHE estimated these forces in an online manner. In a simultaneous fashion, these forces are fed into to NMPC to physically interact with the ceiling during the contact phase. The main objective of this study is to provide a feasible and open-source control framework for a complete test, where the 
practitioners can adopt in inspection operations. Moreover, the battery current changes during the physical interaction are repath planning implementations. In summary, the contributions of this implementation are as follows:

- For the first time, a safety jacketing feature on the controller effort is guaranteed by the proposed nonlinear model predictive controller for the contact-based UAV ${ }^{210}$ inspection operation.

- The contact forces during aerial physical interaction are estimated online by proposed constrained optimizationbased estimation approach to be fed into the constrained optimization-based controller in real time.

- A complete solution considering lightweight inspection subsystems for the UAV is proposed.

- An in-situ contact-based nondestructive test on the ceiling 215 is conducted and the data streamlined via Bluetooth by the flying inspector.

This paper is structured as follows: first, the mathematical model of the UAV is given in Section 2. The considered problem ${ }_{220}$ is formulated in Section 3 . The proposed optimization-based framework consisting of the NMHE and the NMPC is provided in Section 4. The experimental setup, the inspection operation, data collected, and the proposed approach's performance are explained and discussed in Section 5 After the results, a further ${ }_{225}$ discussion is given on the current inspection approaches in Section 6 Consequently, conclusions including future works are drawn in Section 7

\section{Preliminary: UAV Model}

The baseline platform is a four-rotor system and its coordi 230 nate frames are illustrated in Fig. 1. The mathematical model based on [52] is augmented to take the external forces into ac-

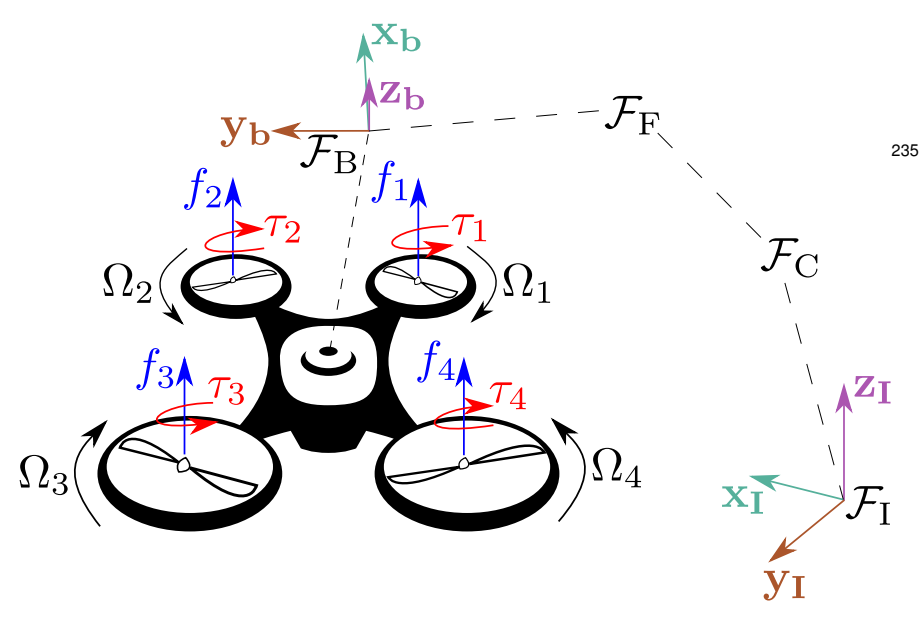

Figure 1: The UAV scheme
For each rotor, the aerodynamic forces and moments are generated by

$$
\begin{aligned}
& f_{i}=\mathrm{c}_{\mathrm{T}} \Omega_{\mathrm{i}}^{2}, \\
& \tau_{i}=\mathrm{c}_{\mathrm{D}} \Omega_{\mathrm{i}}^{2},
\end{aligned}
$$

where $c_{\mathrm{T}}$ and $c_{\mathrm{D}}$ are the trust and drag coefficients for each rotor $i$, where their velocities are indicated by $\Omega$. It is noted that this equation is not valid when the system operates in close proximities, e.g., ceiling and ground effects [53]. Since the system is actuated by the rotors, there is a need to allocate the control actions. For this purpose, the following control allocation matrix is defined,

$$
\left[\begin{array}{c}
F_{z} \\
L \\
M \\
N
\end{array}\right]=\left[\begin{array}{cccc}
\mathrm{c}_{\mathrm{T}} & \mathrm{c}_{\mathrm{T}} & \mathrm{c}_{\mathrm{T}} & \mathrm{c}_{\mathrm{T}} \\
-1 \mathrm{c}_{\mathrm{T}} & 1 \mathrm{c}_{\mathrm{T}} & 1 \mathrm{c}_{\mathrm{T}} & -1 \mathrm{c}_{\mathrm{T}} \\
1 \mathrm{c}_{\mathrm{T}} & 1 \mathrm{c}_{\mathrm{T}} & -1 \mathrm{c}_{\mathrm{T}} & -\mathrm{c}_{\mathrm{T}} \\
\mathrm{c}_{\mathrm{D}} & -\mathrm{c}_{\mathrm{D}} & \mathrm{c}_{\mathrm{D}} & -\mathrm{c}_{\mathrm{D}}
\end{array}\right]\left[\begin{array}{c}
\Omega_{1}^{2} \\
\Omega_{2}^{2} \\
\Omega_{3}^{2} \\
\Omega_{4}^{2}
\end{array}\right],
$$

where $F_{z}$ is the total force generated by the rotors and 1 is the length of the arm which measured from the center of gravity to the center of each rotor. At the same time, the moments are defined as $L, M$ and $N$ on the $\mathbf{x}_{\mathbf{b}}, \mathbf{y}_{\mathbf{b}}$ and $\mathbf{z}_{\mathbf{b}}$ axes (defined on the body) respectively. It is assumed that the total forces and the moments are independent of the defined axis. However, we need to map the orientation of the rigid body from the body frame to the inertial frame. The transformation to map the movement of the body into the earth frame requires us to define rotations and their sequences. In order to transit, two intermediate frames are defined: $\mathcal{F}_{\mathrm{C}}$ and $\mathcal{F}_{\mathrm{F}}$ in which the translational positions can be given in a vector $\xi=[x, y, z]^{\mathrm{T}}$. The following rotation sequence is adopted for an orientation of $\xi^{\mathrm{B}}$ :

- Rotation 1 - $\psi$ yaw angle about axis $\mathbf{z}_{\mathbf{I}}$

- Rotation 2 - $\theta$ pitch angle about axis $\mathbf{y}_{\mathbf{C}}$

- Rotation 3 - $\phi$ roll angle about axis $\mathbf{x}_{\mathbf{B}}$

where,

$$
\xi^{\mathrm{I}}=\mathbf{T}_{\mathrm{IB}} \xi^{\mathrm{B}}=\mathbf{T}_{\psi} \mathbf{T}_{\theta} \mathbf{T}_{\phi} \xi^{\mathrm{B}} .
$$

These transformation is obtained by introducing two additional intermediate frames as can be seen in Fig. 1 Here, the frame $\mathcal{F}_{\mathrm{C}}$ represents the earth frame wherein $\mathbf{x}_{\mathrm{C}}$ is aligned with the UAV's heading. Moreover, the frame $\mathcal{F}_{\mathrm{C}}$ allows the projection between the $\mathcal{F}_{\mathrm{C}}$ and the body frame by a rotation of the pitch angle $\theta$. It is noted that the subscripts $\mathrm{C}$ and $\mathrm{F}$ stand for the coarse and fuselage, respectively. In summary:

$$
\begin{aligned}
& \xi^{\mathrm{I}}=\mathbf{T}_{\psi} \xi^{\mathrm{C}}, \\
& \xi^{\mathrm{C}}=\mathbf{T}_{\theta} \xi^{\mathrm{F}}, \\
& \xi^{\mathrm{F}}=\mathbf{T}_{\phi} \xi^{\mathrm{B}}
\end{aligned}
$$


where

$$
\begin{aligned}
& \mathbf{T}_{\psi}=\mathbf{T}_{\mathrm{IC}}=\left[\begin{array}{ccc}
c_{\psi} & -s_{\psi} & 0 \\
s_{\psi} & c_{\psi} & 0 \\
0 & 0 & 1
\end{array}\right], \\
& \mathbf{T}_{\theta}=\mathbf{T}_{\mathrm{CF}}=\left[\begin{array}{ccc}
c_{\theta} & 0 & s_{\theta} \\
0 & 1 & 0 \\
-s_{\theta} & 0 & c_{\theta}
\end{array}\right], \\
& \mathbf{T}_{\phi}=\mathbf{T}_{\mathrm{FB}}=\left[\begin{array}{ccc}
1 & 0 & 0 \\
0 & c_{\phi} & -s_{\phi} \\
0 & s_{\phi} & c_{\phi}
\end{array}\right], \\
& \mathbf{T}_{\mathrm{IB}}=\mathbf{T}_{\psi} \mathbf{T}_{\theta} \mathbf{T}_{\phi},
\end{aligned}
$$

in which $s_{\star}$ and $c_{\star}$ are the abbreviations for the $\sin (\star)$ and $\cos (\star)$, respectively. Therefore, the translational states can be defined on inertial frame:

$$
\left[\begin{array}{c}
\dot{x} \\
\dot{y} \\
\dot{z}
\end{array}\right]=\mathbf{T}_{\mathrm{IB}}\left[\begin{array}{c}
u \\
v \\
w
\end{array}\right]
$$

where $x, y$ and $z$ are the translational states; $u, v$ and $w$ are the translational velocities. Similarly, the angular states can be defined:

$$
\left[\begin{array}{c}
\dot{\phi} \\
\dot{\theta} \\
\dot{\psi}
\end{array}\right]=R_{\mathrm{r}}\left[\begin{array}{c}
p \\
q \\
r
\end{array}\right]
$$

where $p, q$ and $r$ are the angular rates with the following rotation matrix $\left(\mathrm{t}_{\star}\right.$ is $\left.\tan (\star)\right)$ :

$$
R_{\mathrm{r}}=\left[\begin{array}{ccc}
1 & s_{\phi} \mathrm{t}_{\theta} & c_{\phi} \mathrm{t}_{\theta} \\
0 & c_{\phi} & -s_{\phi} \\
0 & \frac{s_{\phi}}{c_{\theta}} & \frac{c_{\phi}}{c_{\theta}}
\end{array}\right]
$$

The forces on the UAV are given as

$$
\left[\begin{array}{c}
\dot{u} \\
\dot{v} \\
\dot{w}
\end{array}\right]=\left[\begin{array}{c}
0 \\
0 \\
\frac{F_{z}}{\mathrm{~m}}
\end{array}\right]-\left[\begin{array}{c}
q w-r v-\mathrm{g} s_{\phi} \\
r u-p w+\mathrm{g} s_{\phi} c_{\theta} \\
p v-q u+\mathrm{g} c_{\phi} c_{\theta}
\end{array}\right]+\left[\begin{array}{c}
F_{x, \text { ext }} \\
F_{y, \text { ext }} \\
F_{z, \text { ext }}
\end{array}\right],
$$

where $\mathrm{g}$ is the gravity constant and external forces are $F_{x, \text { ext }}, F_{y \text {,ext }}$, and $F_{z \text {,ext }}$ acting on the rigid body axes $\mathbf{x}_{\mathbf{b}}, \mathbf{y}_{\mathbf{b}}$ and $\mathbf{z}_{\mathbf{b}}$, respectively.

Remark 1. The baseline model in (9) is augmented by the additive model, where the disturbances, changing parameters, unmodeled and mismatched dynamics are lumped into the external ${ }^{280}$

The moments acting on the UAV are given by

$$
\left[\begin{array}{c}
I_{x x} \dot{p} \\
I_{y y} \dot{q} \\
I_{z z} \dot{r}
\end{array}\right]=\left[\begin{array}{c}
\left(I_{y y}-I_{z z}\right) q r \\
\left(I_{z z}-I_{x x}\right) p r \\
\left(I_{x x}-I_{y y}\right) p q
\end{array}\right]+\left[\begin{array}{c}
L \\
M \\
N
\end{array}\right]+\left[\begin{array}{c}
L_{\mathrm{ext}} \\
M_{\mathrm{ext}} \\
N_{\mathrm{ext}}
\end{array}\right],
$$

where $L_{\text {ext }}, M_{\text {ext }}$ and $N_{\text {ext }}$ are external torques on the $\mathbf{x}_{\mathbf{b}}, \mathbf{y}_{\mathbf{b}}$ and $\mathbf{z}_{\mathbf{b}}$ axes respectively. Here, the moments of inertias are given by ${ }_{285}$ $I_{x x}, I_{y y}$ and $I_{z z}$.

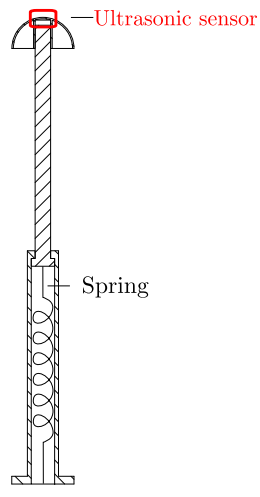

Figure 2: The soft compensation mechanism

\section{Problem Formulation}

In order to avoid a hard contact with the ceiling, a soft compensation mechanism is designed, which is visualized in Fig. 2 Consequently, the phsyical interaction force on $z$ axis can be represented as [54]

$$
\begin{aligned}
F_{z, \text { ext }} & = \begin{cases}0 & \Delta z \leqslant 0, \\
k \Delta z+b \dot{\Delta z} & 0<\Delta z,\end{cases} \\
\Delta z & =l_{\mathrm{s} 0}-l_{\mathrm{s}}(t),
\end{aligned}
$$

where the interaction level is characterized by $\Delta z$. The second order system parameters are characterized by spring cofficient $k$ and the damping coefficient $b$. When the UAV operates in freeflight, the inspection tool's length is indicated by $l_{\mathrm{s} 0}$. After the first touch, $l_{\mathrm{s}}(t)$ represents the displacement of the tool during the contact phase.

Problem 1. In order to conduct an inspection operation while providing safe data, how the system can be autonomously controlled? In order to address this problem, the following subproblems need to be considered:

1. (Interactive tracking) Since the external force is effective on the system as an additive force, a simple example can be given as follows

$$
\dot{\mathrm{x}}=-a \mathrm{x}+\mathrm{u}+\mathrm{p},
$$

where $\mathrm{x}$ is the state vector, $\mathrm{u}$ is the control vector and $a$ is a system parameter. The external forces are indicated by vector $\mathrm{p}$. For a reference $\mathrm{x}_{r}$, the error dynamics can be given by

$$
\dot{e_{\mathrm{x}}}=-a e_{\mathrm{x}}-\mathrm{u}-\mathrm{p}+a \mathrm{x}_{r} .
$$

When a standard feedback controller is applied with a proportional gain $K$, it can be seen that

$$
\dot{e_{\mathrm{x}}}(\infty)=-\frac{\mathrm{p}}{a+K},
$$

where the question arises here in a way that how this error can be suppressed to some extent while respecting system constraints. 
2. (Reachability) In order to reach the target, there are two ${ }_{3 з 0}$ significant factors: (i) UAV is trying to minimize the error; (ii) the tool on the UAV is maximizing the external forces. This problem can be represented as a differential game between the control input and the external forces. The controller action brings the system to a reachable set for ${ }_{335}$ a desired region of $\mathrm{x}_{r}$ while the external forces do the opposite. The external forces are bounded by

$$
F_{\star, \text { ext } \max }=k_{\max } \Delta z_{\max }+b_{\text {max }} \dot{\Delta z_{\text {max }}} .
$$

3. (Basis of the inspection operation) The inspection system ${ }_{340}$ needs to fit into the working space of the surrounding environment and its opening with fully-functional subsystems.

4. (Ultrasonic data stream) The ultrasonic sensor has to maintain contact in certain force ranges while streaming the inspection data.

To address the problem, the control architecture of the closedloop system can be designed depending on the safety and performance specifications for the force interaction. In order to demonstrate the effectiveness of the estimation and control ar- $_{350}$ chitecture for the UAV-tool operation, translational states are considered, where the external forces are dominant on the velocities. In this context; three translational states $(x, y$ and $z$ ), three translational velocities $(u, v$ and $w)$, and unknown external forces $\left(F_{x, \text { ext }}, F_{y, \text { ext }}\right.$ and $\left.F_{z \text {,ext }}\right)$ are estimated by NMHE, and they ${ }_{355}$ are fed into the NMPC. The performance of this scheme is tested experimentally for a reference trajectory including free-flight as well as the interaction phases. In this framework, the unknown external forces are acting to represent disturbances, variable parameters and other uncertainties in the working environment. $\operatorname{In}_{360}$ order to handle such mismatches in the system, an optimizationbased framework is preferred in which the NMHE estimates the three external forces online. By doing so, the proposed NMPC-NMHE framework will adapt itself continuously for the time-varying working conditions. In summary, the differential ${ }_{365}$ states, controls and measurements are given as follows:

$$
\begin{aligned}
\mathrm{x}(\cdot) & =[x, y, z, u, v, w]^{\mathrm{T}}, \\
\mathrm{u}(\cdot) & =\left[F_{z}, \phi, \theta, \psi\right]^{\mathrm{T}}, \\
\mathrm{h}(\cdot) & =\left[x, y, z, u, v, w, F_{z}, \phi, \theta, \psi\right]^{\mathrm{T}} .
\end{aligned}
$$

In the optimization framework, the external forces are defined by augmenting the state vector, where the external force vector is embedded through the parameter class $\mathrm{p}$,

$$
\begin{aligned}
\mathrm{p} & =\left[F_{x, \text { ext }}, F_{y, \text { ext }}, F_{z, \text { ext }}\right]^{\mathrm{T}}, \\
\dot{F}_{\star, \text { ext }} & =0 .
\end{aligned}
$$

\section{Methodology: An Optimization-based Framework}

\subsection{Nonlinear Moving Horizon Estimation}

It may not be possible to precisely measure all the states, parameters or external forces at each time in real-time control applications even with advanced sensors. More importantly, eco-375 nomical reasons motivate the research community to use less and cheaper sensors [55]. Consequently, estimating the states, parameters and external forces is vital in practical control applications. Without loss of generality, Kalman filter is a de facto estimator standard for external forces and state estimation. Even if Kalman filter would provide bias-free estimation when the assumptions meet with the application conditions and weighting matrices of the least-square objective function is well-tuned, it may not incorporate with the constraints on the states, parameters and/or disturbances [56]. However, in a practical implementation, the system needs to handle the constraints because of the physical and environmental constraints. It is significant to highlight the question of why these constraints are not imposed on the controller. Firstly, this approach provides estimating a safe bound as a priori information for the system limits. Secondly, considering the same mathematical model enables the estimator to explore defects in the controller. When the same mathematical model is considered on both estimation and the controller, it is possible to identify the additive segment of the model to capture unmodelled dynamics, uncertainties, disturbances and variable parameters in an online manner.

The system parameters and external forces, which have constraints, direct us to consider another class of estimation algorithm: NMHE. Even if the main idea of NMHE and Kalman filtering are similar in terms of being an iterative parameter and state estimation method, NMHE utilizes an optimization algorithm in order to estimate state or parameter considering a finite and moving window including a fixed number of past measurements. In NMHE, optimization algorithm solves a nonlinear least-squares (in)equality constraint problem. In order to guarantee the estimation reliability, another term called arrival cost is considered in the algorithm. This term takes the past data (before the estimation window) into account, and it considerably contributes to the performance of the estimation by choosing the suitable weight matrices.

Although NMPC and NMHE solve different optimization problems, the similarity of these optimization methods is obvious. The arrival cost approximation (the cost to arrive function) of NMHE corresponds to terminal penalty term (the cost to go function) in NMPC which can also be accepted as an approximation of the infinite horizon cost. On the one hand, NMPC looks ahead throughout the prediction horizon, on the other hand, NMHE looks back over the moving window. In order to estimate the external forces, the constrained optimization problem is formulated with following objective function:

$$
\begin{array}{r}
\min _{\mathbf{x}(.), \mathbf{p}, \mathbf{u}(.)} \int_{t_{k}-t_{E W}}^{t_{k}}\left\|\mathrm{y}_{m}(t)-\mathrm{h}(\mathrm{x}(t), \mathrm{u}(t), \mathrm{p})\right\|_{\mathrm{H}}^{2} d t+ \\
\left\|\begin{array}{c}
\hat{\mathrm{x}}\left(t_{k}-t_{E W}\right)-\mathrm{x}\left(t_{k}-t_{E W}\right) \\
\hat{\mathrm{p}}-\mathrm{p}
\end{array}\right\|_{\mathrm{P}}^{2},
\end{array}
$$

$$
\begin{array}{ll}
\text { subject to } & \dot{\mathrm{x}}(t)=f(\mathrm{x}(t), \mathrm{u}(t), \mathrm{p}), \\
& \mathrm{x}_{\min } \leqslant \mathrm{x}(t) \leqslant \mathrm{x}_{\max }, \\
& \mathrm{p}_{\min } \leqslant \mathrm{p} \leqslant \mathrm{p}_{\max } .
\end{array}
$$

Here, $\mathrm{x}(t) \in \mathbb{R}^{\mathrm{n}}, \mathrm{u}(t) \in \mathbb{R}^{\mathrm{m}}$, and $\mathrm{y}_{m}(t) \in \mathbb{R}^{\mathrm{n}+\mathrm{m}}$ are the states, controls, and measurements respectively. The objective function is constructed based on $\ell_{2}$ norm. The first segment of the 
objective function is stage cost which is penalized by matrix $\mathrm{H}$. The second and last segment of the objective function is arrival ${ }_{435}$ the measurements including state measurement $\mathrm{x}(t)$ and control measurement $\mathrm{u}(t)$. The $t_{k}$ is the current time and the $t_{E W}$ is the estimation window. Unlike the NMPC formulation, the optimization problem including output functions, the integrator, and surements. The positive definite weighting matrices, $\mathrm{H}$ and $\mathrm{P}$ are chosen to obtain adequately precise estimation values by penalizing the deviation of the measured output $h(\cdot)$ and system output including states and controls. The matrix $\mathrm{H}$ is chosen depending covariance matrix of the measurement error. In addition, the matrix $\mathrm{P}$ is assigned depending on the covariance matrix of the estimation error and it is updated throughout the estimation. The bounded parameters are given by $x_{\min }, x_{\max }, p_{\min }$ and $p_{\max }$. The arrival cost is the last term of the objective function. The ${ }^{440}$ terms $\hat{\mathrm{x}}\left(t_{k}-t_{E W}\right)$ and $\hat{\mathrm{p}}$ characterize the summary of the previous estimated values before $\left(t_{k}-t_{E W}\right)$. Readers interested in the solution of NMHE can refer to [57, 58]. When the external forces are provided by NMHE in certain accuracy bounds, NMPC can handle defined Problem 1.1. Readers interested in estimation ${ }^{445}$ accuracy bounds can refer to [59].

\subsection{Nonlinear Model Predictive Control}

As being multi-input-multi-output (MIMO) and underactuated systems, UAVs may not be ideally suitable for individual ${ }^{450}$ and single-input-single-output controllers for different subsysdue to possible selfish behavior of each decentralized agent [60]. Additionally, interactions between subsystems may be strong as it may oblige us to use MIMO techniques. As an optimal state feedback controller, linear quadratic regulator (LQR) is ${ }^{455}$ a well-known MIMO control technique which provides optimal

${ }_{410}$ feedback gains. Although LQR solves the control problem in an optimal way when the mathematical model of the system is precise enough, it cannot handle constraints. What is more, since LQR needs a linearized model of the nonlinear system around ${ }^{460}$ an equilibrium point, highly nonlinear operations, such as aerial 415 physical interactions [61], may not be controlled by such linear controllers around all operating points, especially when the system has to operate outside of the linearization region. In order to capture all the dynamic behavior of such nonlinear systems, some in-between solutions are proposed, such as piecewise lin420 ear models, linear time-varying and linear parameter-varying models. Difficulties associated with the piecewise linear models emerge when the system switches from one operating point to another one. Even supposing the linear models would alleviate the computation burden of the optimization problem, the mathematical model of the UAV-tool operation, which includes nonlinearities both on its inputs and states, and also complexities in its control allocation for the physical interaction tasks might necessitate using a fully nonlinear model. In light of these motivations, the nonlinear version of MPC, NMPC, is preferred in this paper for the control of the UAV-tool system. The reachability problem defined in Problem 1.2 is transformed to be a min problem instead of min-max problem. Since the disturbance on the system is introduced within the reference, we have used proof proposed in [62]. Therefore, NMPC is considered to be a centralized controller with the following expressions,

$$
\begin{array}{r}
\min _{\mathbf{x}(.), \mathbf{u}(.)} \int_{t_{k}}^{t_{k}+t_{h}}\left(\left\|\mathrm{x}_{r}(t)-\mathrm{x}(t)\right\|_{\mathrm{Q}}^{2}+\left\|\mathrm{u}_{n}(t)-\mathrm{u}(t)\right\|_{\mathrm{R}}^{2}\right) d t+ \\
\left\|\mathrm{x}_{r}\left(t_{k}+t_{h}\right)-\mathrm{x}\left(t_{k}+t_{h}\right)\right\|_{\mathrm{S}}^{2},
\end{array}
$$

subject to

$$
\begin{aligned}
& \mathrm{x}\left(t_{k}\right)=\hat{\mathrm{x}}\left(t_{k}\right), \\
& \dot{\mathrm{x}}(t)=f(\mathrm{x}(t), \mathrm{u}(t), \mathrm{p}), \\
& \mathrm{x}_{\min } \leqslant \mathrm{x}(t) \leqslant \mathrm{x}_{\max }, \\
& \mathrm{u}_{\min } \leqslant \mathrm{u}(t) \leqslant \mathrm{u}_{\max } .
\end{aligned}
$$

Here, $t_{h}$ specifies the horizon length for prediction and control. Reference trajectory is given by $\mathrm{x}_{r}$ and nominal input is expressed by $\mathrm{u}_{n}$. Similar to the NMHE formulation, $\ell_{2}$ norm is used in the objective function, which consists of two segments: (i) stage cost; (ii) terminal cost. In the stage cost, there are two different vectors penalized by the weight matrices: (i) change in the state vector by Q; (ii) change in the control vector by $\mathrm{R}$. The terminal cost is imposed to provide stability for the controller [63]. The constraints on the states and inputs are given by $x_{\min }$, $\mathrm{x}_{\max }, \mathrm{u}_{\min }$ and $\mathrm{u}_{\max }$. The semi-positive definite matrices $\mathrm{Q}$ and $\mathrm{S}$, and the positive definite matrix $\mathrm{R}$ are weighting parameters to provide performance requirements for the defined interactive tracking problem. The weight matrix Q penalizes the deviation between the reference trajectory and the current state, whereas R penalizes the differences between nominal input values and current inputs, and $\mathrm{S}$ penalizes the deviation between the reference and the model output at the end of the horizon.

The proposed approach is illustrated in Fig. 3 In a general perspective, most of the control approaches heavily rely on modeling accuracy. However, the nature of the introduced problem includes variation in the model (e.g., variable thrust coefficient when flying close to the ceiling), disturbances (e.g., arbitrary forces during the contact phase), uncertain environment (e.g., the position of the ceiling). One of the alternatives is to consider

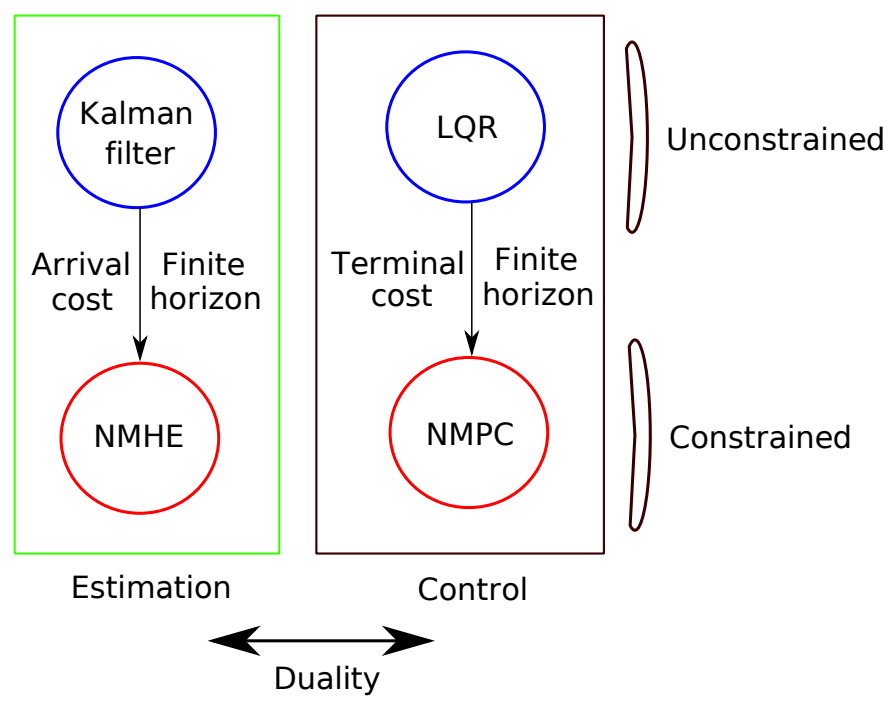

Figure 3: NMHE - NMPC scheme 
a model-free approach, e.g., an experimental evaluation is given in [64]. Unfortunately, the stability is not provided based on the whole system consisting of the UAV and the controller, which is500 vital for safety-critical systems [65]. Furthermore, the learning system may diverge from the initial conditions. For the modelbased approaches, there is a dilemma between the accuracy level of the design and the complexity level of the system. Depending ${ }_{505}$ on preference, modeling mismatch can be large or small, where they can be suppressed by robust and/or adaptive approaches [66]. For a linear case, it is possible to leverage Kalman filter LQR pair for a system, where the constraints are trivial. However, in our proposed approach, this pair is indirectly utilized to510 approximate infinite horizon within arrival and terminal costs while respecting the system constraints. Furthermore, NMPC and NMHE can be considered as a dual problem due to having the same mathematical model, where the system is represented by the sum of a nominal and additional parts [67]. In this context, the external forces, uncertainties, disturbances and the modeling mismatched are lumped to the additional part, which is estimated online by NMHE. These values are fed into the NMPC to handle free-flight and contact phases in real-time.

\section{Experiments}

The block diagram of the proposed approach is visualized in Fig. 4. To address Problem 1.3, the system parameters are adopted from [54], where its size and subcomponents are feasible to conduct the inspection operation. The UAV is marked to have experimented in motion capture lab, which is based on the 515 Optitrack system with 8 cameras providing localization at 240 $\mathrm{Hz}$

\subsection{Closed-loop Control System}

In the proposed scheme, the task-based trajectories are generated by the block called inspection planner. In this application, the trajectories include free-flight and the contact phase for the UAV to dock the ceiling. The NMPC block utilizes an optimization routine in a receding horizon manner to follow arbitrary task-based trajectories. This phase also comprises the vertical ${ }_{520}$ force and angular trajectory generation to be fed into the lowlevel controller. The angular trajectories planned by NMPC are passed to the proportional (P) controller at first. The output of the $\mathrm{P}$ controller is given to the PID for the angular rate reference following. The output of the PID and the vertical force generated by the NMPC are directed into the control allocation matrix defined in (2). Therefore, this block performs open loop computations for the rotor velocities. By receiving the measurement function given in 16c, NMHE employs the estimation phase with an optimization routine in a receding horizon manner similar to the NMPC. At this stage, external forces are estimated by NMHE to be fed into the NMPC simultaneously. This information allows the NMPC to handle the contact phase. It is noted that the nominal case where the controller is lacking the external force information may not reach the higher force interaction levels. The following constraints are imposed on the NMPC and NMHE:

$$
\begin{aligned}
0.5 m g & \leqslant F_{z} \leqslant 1.25 m g, \\
-6 & \leqslant F_{z, \text { ext }} \leqslant 2 .
\end{aligned}
$$

Even if the number of constraints increase the computational burden, it provides an initial value for the optimization problem in a feasible region. In the algorithm, the initial values are obtained via arithmetic mean for the lower and upper bounds. The estimation window length is chosen to be 40 with $10 \mathrm{~ms}$ sampling time. The following weight matrix is used in NMHE problem:

$$
\mathrm{H}=10^{-4} \cdot \operatorname{blkdiag}\left(25 \cdot \mathbf{I}_{6}, 0.01,2.5 \cdot \mathbf{I}_{3}\right),
$$

which is specified based on standard deviations of the measurements. At the begining of the implementation, the following initial values are specified:

$$
\begin{aligned}
\hat{\mathbf{x}} & =\mathbf{0}_{6 \mathrm{x} 1}, \\
\mathrm{p} & =\mathbf{0}_{3 \times 1}, \\
\mathrm{P}(0) & =\operatorname{blkdiag}\left(10^{-2} \cdot \mathbf{I}_{6}, 10^{-3} \cdot \mathbf{I}_{3}\right) .
\end{aligned}
$$

The weights on the arrival cost affect the estimation accuracy. There is a balance between the past measurements and the selected estimation window. The higher values of the weights

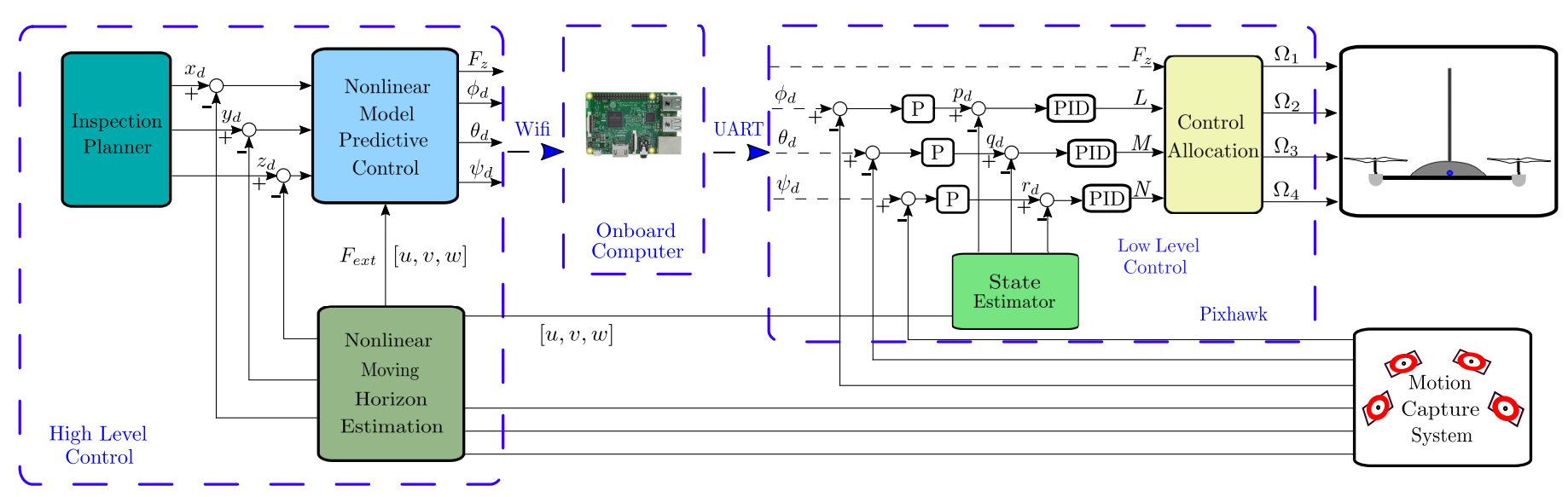

Figure 4: The proposed approach: block diagram of the control and estimation algorithm 
tend to rely more on past data. However, the contact phase may require to take the last section of the measurements into account due to having different dynamics. This is the reason why the weights are chosen comparably low. We avoid extreme ong as the NMHE algorithm gives estimation values in a certain precision, which is defined in the algorithm depending on the Karush-Kuhn-Tucker (KKT) conditions, the NMPC performs command following for the task-based trajectories. The predicion and control horizon lengths are also chosen to be 40 in the closed loop scheme. The following weight matrices are used in the NMPC problem:

$$
\begin{aligned}
\mathrm{Q} & =\operatorname{blkdiag}(30,30,10,1,1,2.5), \\
\mathrm{R} & =\operatorname{blkdiag}\left(4 \times 10^{-2}, 30,30,80\right), \\
\mathrm{S} & =\operatorname{blkdiag}(60,60,20,2,2,5),
\end{aligned}
$$

where the large values of $\mathrm{Q}$ as compared to $\mathrm{R}$ reflect an intention to drive the system to the target point with the expense of the vertical force $F_{2}$, its weight is kept less. The weights on the attitude angles are chosen higher than that of standard control weight matrices to avoid extreme angular rates. The weights of the translational velocities are less than that of translational positions. Its effect is similar to the damping effect, where the higher weights on the translational velocities result in a sluggish behavior. For a more systematic tuning, a batch simulation with learning can be preferred as can be seen in [68]. The optimization problems in (18) and (19), which are also called dual ${ }^{585}$ problems, are solved by the same algorithm. The dual problems are executed in a simultaneous manner. Since the considered optimization problem is high computation-demanding, the realtime iteration (RTI) approach is used in ACADO toolkit which stands for the "automatic control and dynamics optimization, 69]. It is an open-source software platform written in $\mathrm{C}++$ which provides user-friendly structure and code flexibility. Even if it is designed to be a self-contained software package, it could be easily interfaced with other software packages. What is more, ACADO creates tailored C codes for a designed optimization ${ }^{595}$ problem [70].

Solving the dual problem is performed by using multiple shooting method throughout the horizon where the nonlinear model is discretized. Additionally, the defined horizon is equally divided into subintervals. One of the successful proposals is given in [71] to solve differential equations over these subin 600 tervals using the multiple shooting method. It provides fixed size integration step instead of an adaptive size which comes along with a cost. The integration algorithm and step size are defined depending on the system behavior. In the algorithm, 40 prediction intervals. Then, RTI performs single sequential quadratic programming (SQP) iteration by considering GaussNewton approximation for each interval. In each sequential step, quadratic approximations are imposed when the cost function and the constraints are evaluated. Thereafter; qpOASES, which ${ }^{610}$ is based on an active set method and one of the most powerful tools for QP-type problems [72], solves the obtained QP-type

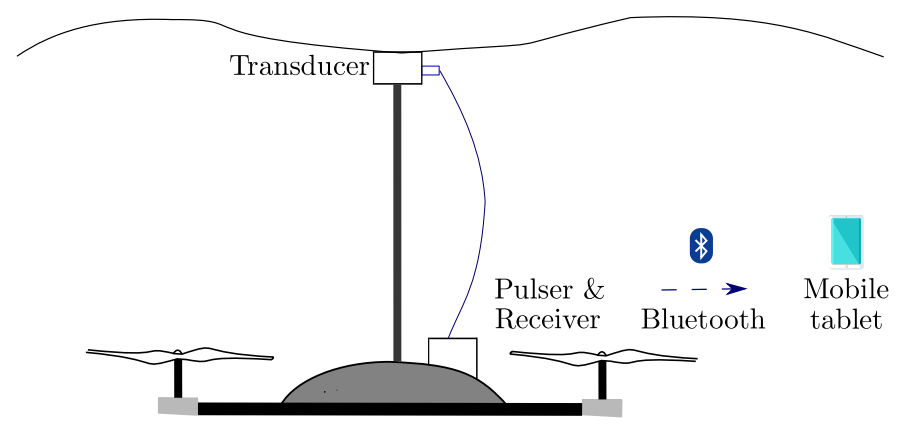

Figure 5: The proposed flying inspector

problem. This process is repeated until the KKT values are minimized. In order to obtain a (sub)optimal solution from the nonlinear programming, KKT conditions should be satisfied. By using the prior information, the shifting technique is utilized for the subsequent problems within the algorithm. Consequently, former control and state variables are considered as a warm start to perform single SQP step for the fast solution.

\subsection{Working Principle of the Inspection Operation}

The acoustic waves propagating in solid materials are characterized by the velocity, wavelength, and the frequency. Since the velocity is specified by the material, the frequency and wavelength can be modified for specific applications, e.g., in a case where higher frequencies are required for the test. Without loss of generality, the sensitivity and resolution of the detection increase when the higher frequency signals are imposed. However, the sound waves travel on a material similar to the Hooke's and Newton's rules. The sound waves propagation is analogous to spring's displacement, wherein a force applied on a system can be balanced by another force in the opposite direction. In this case, the spring coefficient corresponds to the longitudinal wave ultrasonic velocity of the material. Therefore, the speed of the sound in a material depends on the material characteristics which are based on the elastic constant and density. In this context, it is possible to use a suitable transducer to conduct a nondestructive test for the surroundings. To address Problem 1.4, a complete system is schemed, which is illustrated in Fig. 5

\subsection{Calibration of the System}

The main parts of the inspection system are given in Fig. 6 . The ultrasonic device (US Smart) generates and receives the signals and streamlines the data to a mobile device via Bluetooth. This ultrasonic device has the ability to detect various subsurface defects in different materials including welds, rails, and composites. In this context, high-frequency sound waves are sent into the object to identify the potential defects without damaging the surface. There are two main quantities: (i) the total time for the sound to travel through the material; (ii) the received signal's amplitude. In the case of no damage, the thickness of the object can be calculated by

$$
\mathrm{T}_{\mathrm{m}}=\mathrm{c}_{\mathrm{v}} t_{\mathrm{f}} / 2 \text {, }
$$




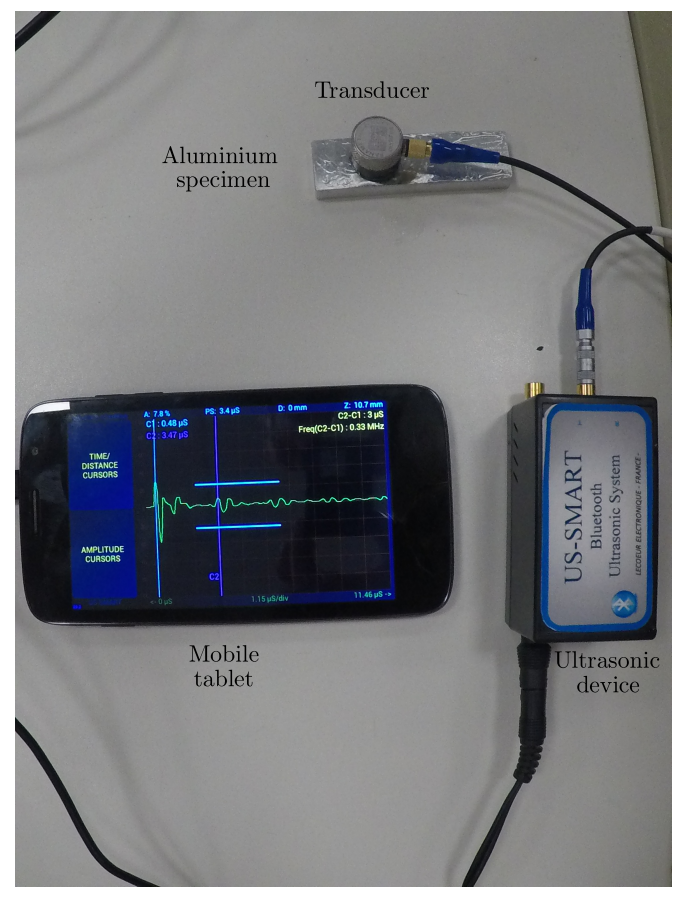

Figure 6: The inspection subsystems

where $T_{m}$ is the thickness of the material, $c_{v}$ is the sound velocity ${ }_{640}$ and the $t_{f}$ is the total flight time. In the case of the crack, there will be additional information due to having the other reflections, which can characterize the crack and/or hollow in the material.

The selected sensor's specification can be seen in Table 1 .

The hollow inside the specimen can be seen in Fig. 7 and the ${ }_{645}$

\begin{tabular}{lll}
\hline Frequency & Size & Type \\
\hline $2.25 \mathrm{MHz}$ & $13 \mathrm{~mm}$ & V106-RM \\
\hline
\end{tabular}

Table 1: Transducer Properties

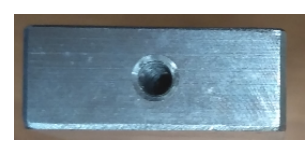

Figure 7: The hollow inside aluminium

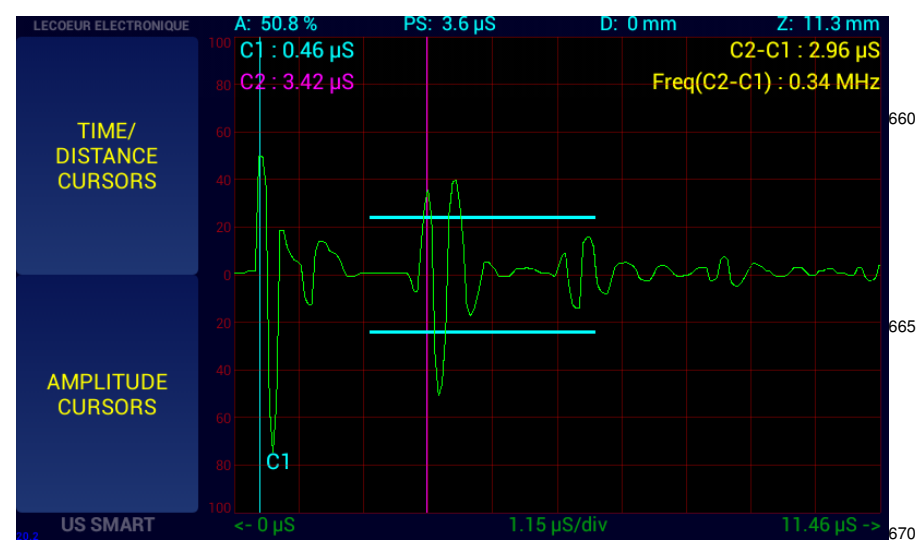

Figure 8: The inspection of hollow inside aluminium output of the calibration test can be seen in Fig. 8. The first part of the signal is marked with the line $\mathrm{C} 1$ and the first reflection from the hollow is marked with the line $\mathrm{C} 2$. The first part of the signals called as near-field and it is characterized by the diameter of the transducer and the wavelength of the signals. After they are placed on the system response, the time of flight is given by the ultrasonic device which directly specifies the location of the hollow inside material using (24). The ultrasonic range is accepted above the human hearing range $(20 \mathrm{kHz})$. The general ultrasonic applications for the nondestructive tests span between $100 \mathrm{kHz}$ to $50 \mathrm{Mhz}$. Since its wavelength is not long, it can be reflected on small surfaces inside a solid, e.g., aluminum. This allows detecting the defects, hollows and/or cracks when it is used for the subsurface inspection.

\subsection{Inspection in the Air}

The system uses the force-based nonlinear model predictive control approach. The system during the operation can be seen in Fig. 9. In order to conduct the contact-based inspection operation, there is a need to be in contact with the ceiling in certain force ranges. In this context, the constraint on the controller provides safety jacketing for the instrumented parts.

The reference is set to be in contact with the ceiling in high force ranges. The response and the output of the transducer are observed at the same time. Before the compression of the spring phase, the transducer did not provide the reflection pulse from the system. This corresponds to the initial phase of the system response as can be seen from Fig. 10. In order to follow the reference, the system needs to compress the compliance mechanism, which required higher vertical force values as compared to the hover case. The force estimation by NMHE is given in Fig. $10 \mathrm{c}$. These values are fed into the NMPC and the corresponding vertical force values can be seen in Fig $10 \mathrm{~b}$ In the compression of the spring phase, the system started to stream the data at 3.5 $\mathrm{N}$ (estimated force). When it comes to the $5.5 \mathrm{~N}$ ranges, the inspection data streamed successfully to the Bluetooth device. Even if the system works at the higher force ranges, the control actions lie within the predefined limits. One of the important aspects is the mission time of the UAV and the current drawn by the battery is given in Fig. 10d. These values indicate that the mission time can be shorter when the system conducts a contactbased inspection, which requires more energy as compared to the ones where the UAV flies without physical interaction. Readers interested in an analysis considering flight time as well as battery lifetime for the flight in close proximities can refer to [73].

In order to eliminate acoustic impedance mismatch between the transducer and the test material, a couplant (Olympus Couplant D) is used. It removes the air gap in the contact phase. The inspection data is also given in Fig. 11 during the operation. Since the ultrasonic velocity in acrylic is $2730 \mathrm{~m} / \mathrm{sec}$, the thickness of the material is verified using (24). The material thickness is calculated as $10.92 \mathrm{~mm}$, which is in acceptable accuracy range for the thickness of $10 \mathrm{~mm}$. Moreover, the Fig. 6 is also validated by the proposed approach during the flight. Since there is no ground truth for the external forces, the estimated 


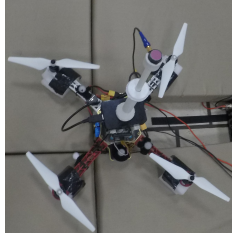

(a) The instrumented UAV

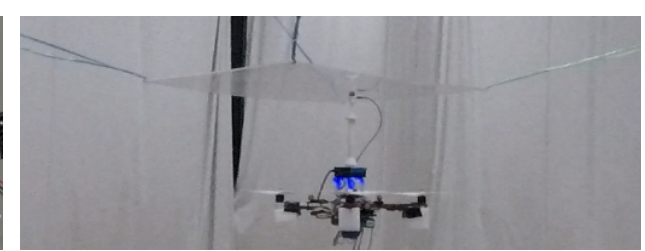

(b) The UAV in contact
Figure 9: Flying inspector conducts subsurface inspection

values for the altitude and the vertical velocity by NMHE are presented in Fig. 12

The proposed approach is a generic method and it can be applied to different real time scenarios. The computation times are given in Fig. 13 and summarized in Table 2 Since the constraints on the vertical forces are activated during the mission, it increases the computation time on the controller. However, proposed approach still provides a feasible operation in realtime. For the inspection operation on curvature surfaces, there are two potentials: (i) generating references on attitude angles or torques, (ii) adding an omnidirectional tool. With our proposed approach, a reference management system can be leveraged to generate feasible angles to maintain inclined interaction with the

\section{Different Inspection Approaches}

In Table 3 , current approaches to inspect surrounding environments can be seen. Due to having payload limitation on the UAV, the focus is given to sonic-based approaches. In this context, it is concluded that the ultrasonic methods are one of the feasible methods to detect the defects, hollows and/or cracks of ceiling structures. Its advantages and disadvantages are summarized in Table 4 As a proof of concept, the UAV is instrumented by a transducer, which can be seen in Fig. 14 1 . In order to conduct a test, a pulse generator needs to be used externally for the transducer to receive the signals and the corresponding reflections. Therefore, a lightweight tool (US Smart) is selected to be added on the UAV. This ultrasonic device is powered by Li-Ion battery and transmits the real-time inspection data via Bluetooth. Although it is possible to conduct in-service nondestructive inspection tests, they need to be properly verified by analyzing the data.

The inspection operation requires several subsystems which come with a cost in terms of the payload for the aerial vehicles.

${ }^{1}$ Image Credit: Olympus Corporation

\begin{tabular}{lccc}
\hline & $\begin{array}{l}\text { Min. Comp. } \\
\text { Time (ms) }\end{array}$ & $\begin{array}{l}\text { Ave. Comp. } \\
\text { Time (ms) }\end{array}$ & $\begin{array}{l}\text { Max. Comp. } \\
\text { Time (ms) }\end{array}$ \\
NMPC - Interaction & 0.84 & 9.80 & 63.03 \\
NMHE - Interaction & 2.82 & 3.74 & 12.36 \\
\hline
\end{tabular}

Table 2: Computation Times: NMPC and NMHE for Ceiling Inspection

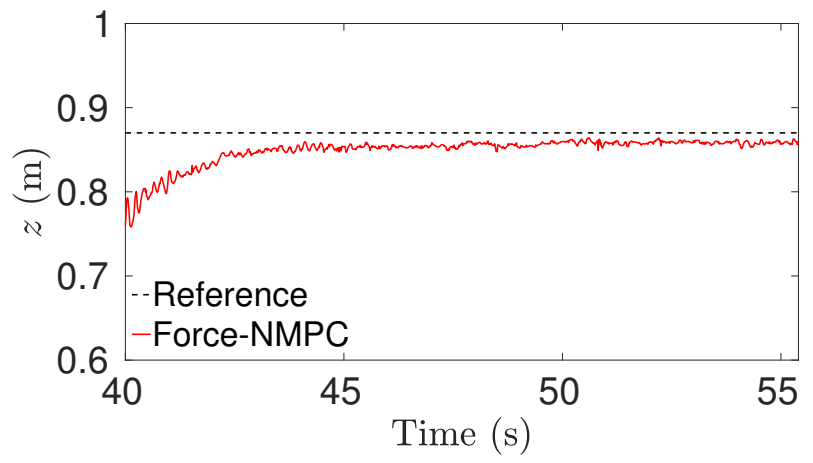

(a) The system performance in vertical axis

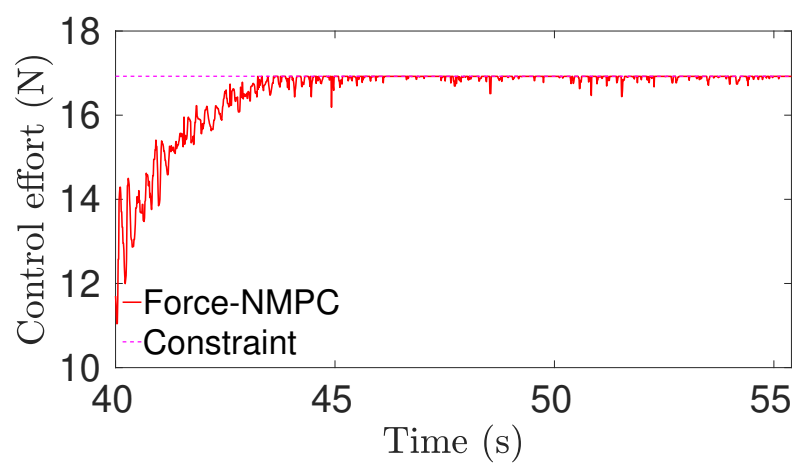

(b) Controller effort

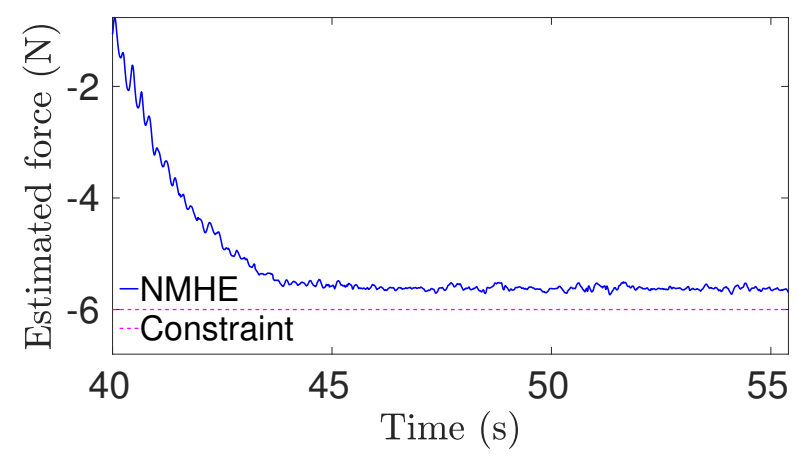

(c) Force estimation

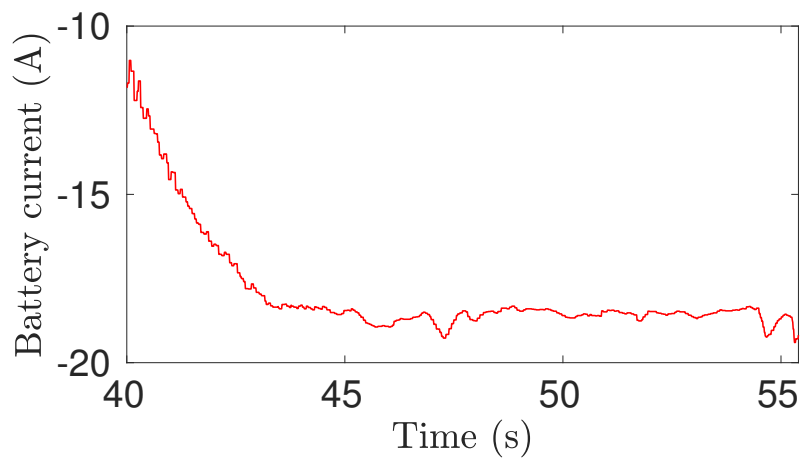

(d) Battery state

Figure 10: The system performance for the inspection test 


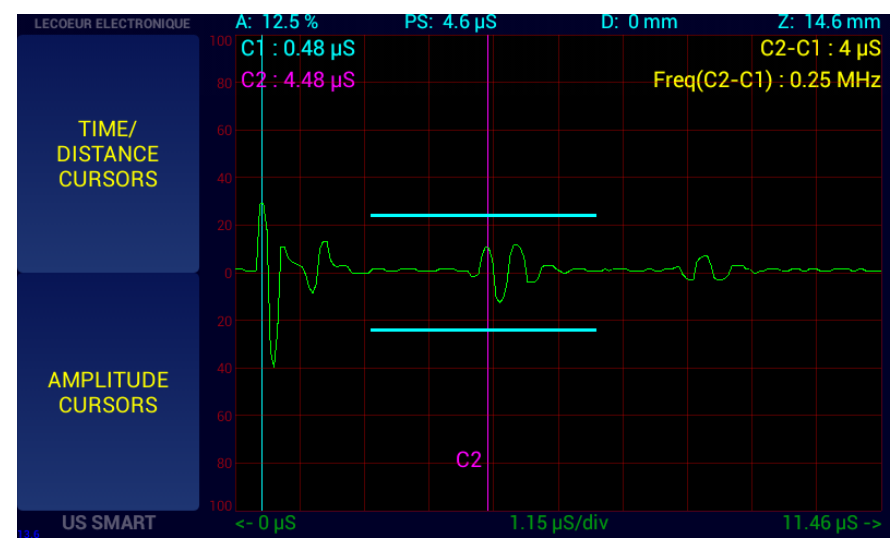

Figure 11: The inspection of thickness for an acrylic

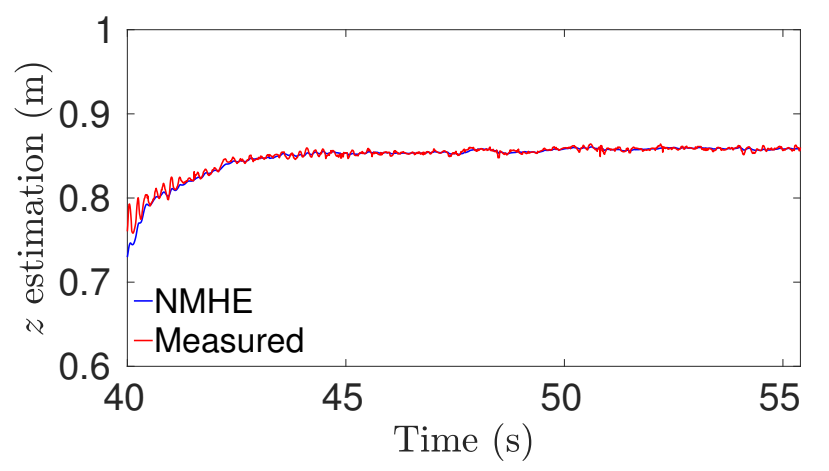

(a) Altitude

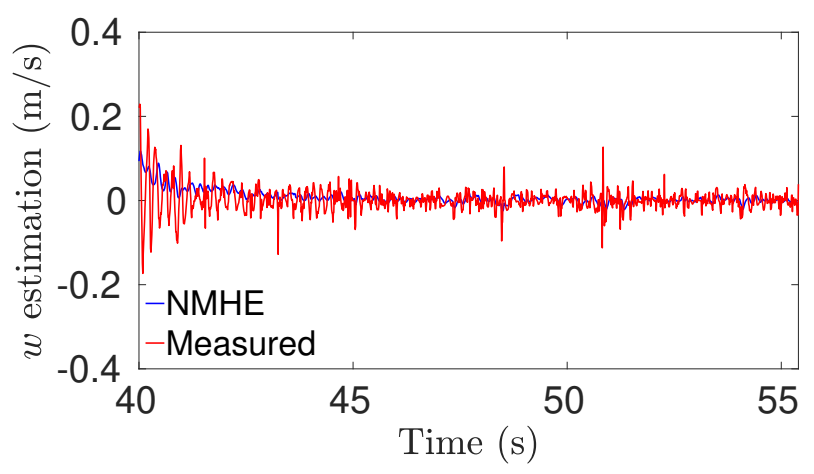

(b) Vertical force

Figure 12: The NMHE performance on the state estimations

study, where lightweight flying inspector subsystems are identified and experimentally validated by the proposed optimization- 735 based framework. This approach provides precise control while staying in predefined safety limits.

\section{Conclusions and Future Works}

In this paper, a feasible contact-based inspection operation in the air is identified. In order to provide safe and applicable operation, a lightweight ultrasonic device to pulse and receive signals is added to the system. This device streams the ultra-

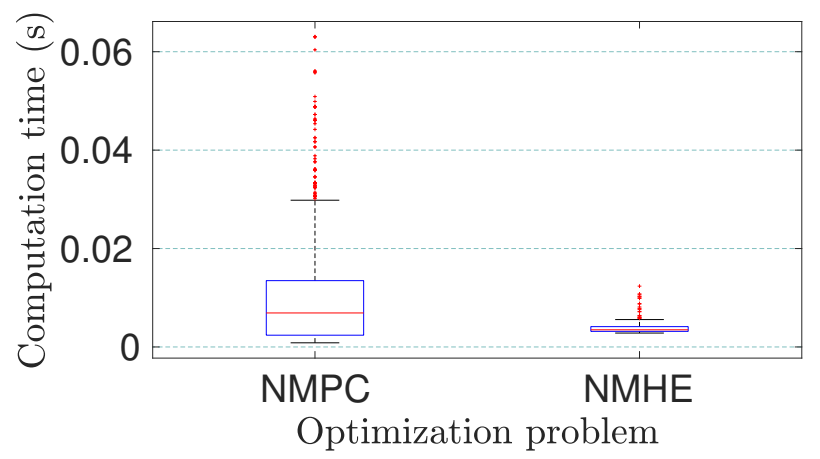

Figure 13: Computation times: NMPC and NMHE

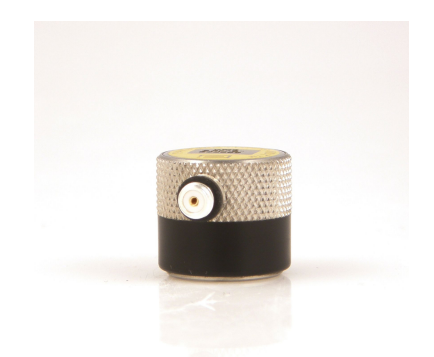

Figure 14: A transducer for contact inspection

reach certain force ranges is validated for the specified inspection subsystems. It is achieved to collect inspection data while autonomously staying in predefined constraint limits. For this purpose, a force-based predictive control approach is proposed to investigate interactions during the contact phase operation in close proximities to the surroundings. The main contribution of this study lies in; modeling, control of the UAV interaction problem and a practical approach for the inspection. A constrained optimization-based algorithm is designed to identify the external forces coming from the interaction tool and environment. Therefore, external forces are included in the system representation. Due to having an interaction task, it is indispensable to guarantee safety jacketing constraints as a feature. For the controller to be aware of the unmodelled existing conditions, the external forces must be estimated in safe bounds. Similarly, the output of the controller needs to respect the constraints for a desired and stable physical interaction. It has been shown through experiments that the proposed approach is efficient in terms of performance and applicability. The external force information increases the model size but an efficient open-source solver is adapted to leverage the problem, which can solve nonlinear predictive control and nonlinear moving horizon estimation problems, in milliseconds.

With this successful proof-of-concept demonstration of the proposed system, the primary goal is to combine the overall system for the in-situ inspection of hard-to-reach places. In terms of the underlying optimization problem, a confidence interval can be defined in which the external forces can be fed into the controller when the defined confidence interval is satisfied for the online estimations. In terms of the proposed system, a battery and battery aging model can be considered to improve the estimation of the total task time for the inspection operations 


\begin{tabular}{|c|c|c|c|}
\hline Method & Instrumentation & Application & Remarks \\
\hline $\begin{array}{l}\text { Vision } \\
\text { based }\end{array}$ & Camera & $\begin{array}{l}\text { Concrete, } \\
\text { steel and } \\
\text { masonry } \\
\text { structures }\end{array}$ & $\begin{array}{l}\text { Detects surface orientation } \\
\text { and condition. } \\
\text { Not suitable for delamination. }\end{array}$ \\
\hline $\begin{array}{l}\text { Strength } \\
\text { based }\end{array}$ & $\begin{array}{l}\text { Schmidt } \\
\text { hammer }\end{array}$ & $\begin{array}{l}\text { Concrete, } \\
\text { rock } \\
\text { strength } \\
\text { for surface }\end{array}$ & $\begin{array}{l}\text { Measures rebound of spring } \\
\text { loaded mass. } \\
12 \text { reading is required. } \\
\text { It is based on impact. }\end{array}$ \\
\hline $\begin{array}{l}\text { Strength } \\
\text { based }\end{array}$ & $\begin{array}{l}\text { Windsor } \\
\text { probe }\end{array}$ & $\begin{array}{l}\text { Concrete } \\
\text { structures }\end{array}$ & $\begin{array}{l}\text { Measures penetration resistence } \\
\text { for relative strength. } \\
\text { The length of the probe } \\
\text { is measured by depth gauge. }\end{array}$ \\
\hline $\begin{array}{l}\text { Strength } \\
\text { based }\end{array}$ & Flat-jack & $\begin{array}{l}\text { Masonry } \\
\text { structures }\end{array}$ & $\begin{array}{l}\text { Measures resistence and } \\
\text { deformation by uniform depth. } \\
\text { It is partially destructive } \\
\text { due to having a cut. }\end{array}$ \\
\hline $\begin{array}{l}\text { Strength } \\
\text { based }\end{array}$ & Shock-tube & $\begin{array}{l}\text { Concrete } \\
\text { structures }\end{array}$ & $\begin{array}{l}\text { Measures dynamic responses } \\
\text { against shock waves. } \\
\text { It identifies defects by } \\
\text { detecting arrival time of waves. }\end{array}$ \\
\hline $\begin{array}{l}\text { Sonic } \\
\text { based }\end{array}$ & $\begin{array}{l}\text { Impact-hammer \& } \\
\text { Contact }\end{array}$ & $\begin{array}{l}\text { Concrete } \\
\text { structures \& } \\
\text { Steel }\end{array}$ & $\begin{array}{l}\text { Measures velocity of a pulse } \\
\text { generated by transducer. } \\
\text { It identifies cracks and hollows } \\
\text { based on pulses travel time. }\end{array}$ \\
\hline $\begin{array}{l}\text { Magnetic } \\
\text { based }\end{array}$ & $\begin{array}{l}\text { Magnetic } \\
\text { flux } \\
\text { leakage }\end{array}$ & $\begin{array}{l}\text { Steel } \\
\text { structures }\end{array}$ & $\begin{array}{l}\text { Measures velocity of a pulse } \\
\text { generated by transducer. } \\
\text { It detects corrosions. }\end{array}$ \\
\hline $\begin{array}{l}\text { Electric } \\
\text { based }\end{array}$ & Resistimeter & $\begin{array}{l}\text { Steel \& } \\
\text { concrete } \\
\text { structures }\end{array}$ & $\begin{array}{l}\text { Measures the resistence to } \\
\text { identify corrosion or crack. }\end{array}$ \\
\hline $\begin{array}{l}\text { Termography } \\
\text { based }\end{array}$ & $\begin{array}{l}\text { Thermal } \\
\text { radiation }\end{array}$ & $\begin{array}{l}\text { Steel \& } \\
\text { concrete } \\
\text { masonry } \\
\text { structures }\end{array}$ & $\begin{array}{l}\text { Measures thermal continuity } \\
\text { of the structure. }\end{array}$ \\
\hline $\begin{array}{l}\text { Radar } \\
\text { based }\end{array}$ & $\begin{array}{l}\text { Ground } \\
\text { penetrating } \\
\text { radar }\end{array}$ & $\begin{array}{l}\text { Steel \& } \\
\text { concrete } \\
\text { structures }\end{array}$ & $\begin{array}{l}\text { Measures electromagnetic } \\
\text { energy level. } \\
\text { It detects defects depending } \\
\text { on difference between dielectric } \\
\text { constants. }\end{array}$ \\
\hline $\begin{array}{l}\text { Radiography } \\
\text { based }\end{array}$ & $\begin{array}{l}\text { X-ray, } \\
\text { gamma } \\
\text { radiation }\end{array}$ & $\begin{array}{l}\text { Steel \& } \\
\text { concrete } \\
\text { structures }\end{array}$ & $\begin{array}{l}\text { Measures amount of absorbed } \\
\text { radiation. } \\
\text { It can detect the hollows } \\
\text { and cracks. }\end{array}$ \\
\hline $\begin{array}{l}\text { Endoscopy } \\
\text { based }\end{array}$ & Endoscope & $\begin{array}{l}\text { Steel \& } \\
\text { concrete } \\
\text { structures }\end{array}$ & $\begin{array}{l}\text { Measures optically through } \\
\text { a hole to detect a sealed object. } \\
\text { It can identify possible defects. }\end{array}$ \\
\hline
\end{tabular}

Table 3: Inspection Methods of Surrounded Environments

\begin{tabular}{ll}
\hline Avantages & Disadvantages \\
\hline $\begin{array}{l}\text { Surface and subsurface } \\
\text { discontinuties can be identified. }\end{array}$ & $\begin{array}{l}\text { It needs to be in contact. } \\
(\sim 1 \mathrm{sec})\end{array}$ \\
$\begin{array}{l}\text { The penetration depth } \\
\text { other contact methods. }\end{array}$ & $\begin{array}{l}\text { It requires more skills } \\
\text { than other methods. }\end{array}$ \\
$\begin{array}{l}\text { One side of contact is enough. } \\
\text { Hard to inspect }\end{array}$ \\
$\begin{array}{l}\text { High accuracy of determining } \\
\text { reflector position. }\end{array}$ & $\begin{array}{l}\text { Hard to inspect cast iron } \\
\text { and other coarse-grained } \\
\text { materials. }\end{array}$ \\
$\begin{array}{l}\text { Instantaneous results can be } \\
\text { obtained thanks to electronic parts. }\end{array}$ & $\begin{array}{l}\text { Parallel oriented linear } \\
\text { defetcs may not be identified. } \\
\text { Standart use of calibration } \\
\text { and characterization of the } \\
\text { detects are required. }\end{array}$ \\
\hline $\begin{array}{l}\text { Detailed visualization can be } \\
\text { obtained with minimal preperation. }\end{array}$ & 755 \\
\hline
\end{tabular}

Table 4: Advantages and Disadvantages of Sonic-based Methods
[74].

\section{Appendix}

A typical tunnel opening pictures are given in Fig. 15 .

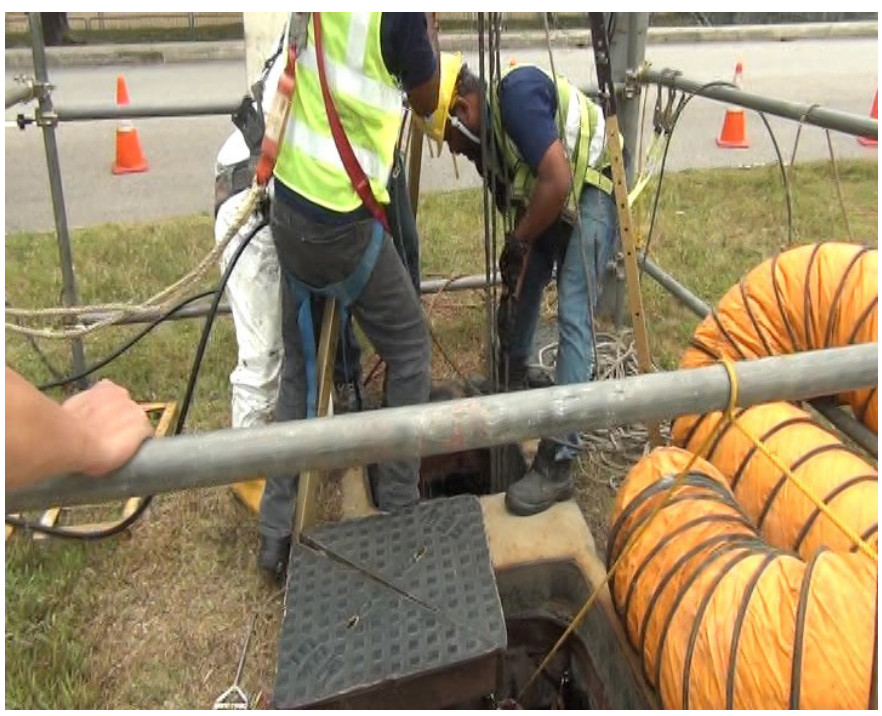

(a) On-going work at the tunnel opening

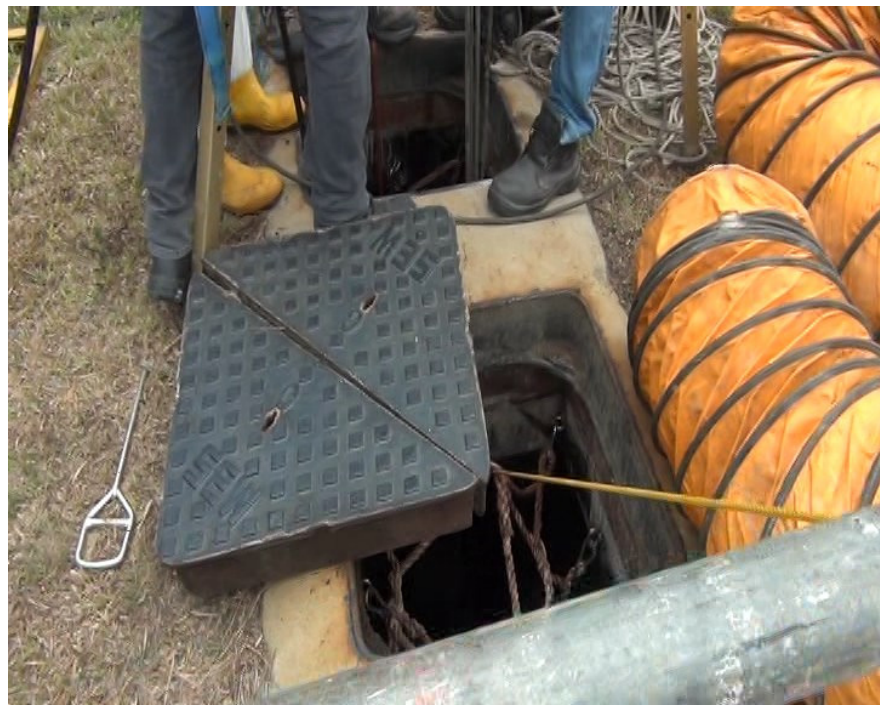

(b) A closer view of the tunnel opening, its size: $60 \times 60 \mathrm{~cm}$

Figure 15: Deep sewerage tunnel system opening

\section{Acknowledgements}

The authors wish to thank for conducting the research work with support from the Energy Research Institute @ NTU (ERI@N) as well as the SINGA research scholarship (SING-2014-2-0256). The authors would like to thank Dr. David Fan Zheng for providing the ultrasonic sensor. The authors also would like to acknowledge Dr. Yu Xudong for his help during the experiments. 


\section{References}

760

[1] M. Alsharqawi, T. Zayed, S. A. Dabous, Integrated condition rating and forecasting method for bridge decks using Visual Inspection and Ground

1. Penetrating Radar, Automation in Construction 89 (2018) 135-145. doi: $10.1016 / j$. autcon.2018.01.016

[2] S. Kawahara, M. Shirato, N. Kajifusa, T. Kutsukake, N. Kajifusa, T. Kutsukake, Investigation of the Tunnel Ceiling Collapse in the Central Expressway in Japan in: Transportation Research Board 93rd Annual Meeting no. 14-2559, 2014, last access date: 2/5/2019. URL https://trid.trb.org/view/1288364

[3] M. Ikuma, Maintenance of the undersea section of the Seikan Tunnel ${ }_{840}$ Tunnelling and Underground Space Technology 20 (2) (2005) 143-149. doi:10.1016/j.tust.2003.10.001

[4] H. Mashimo, T. Ishimura, State of the art and future prospect of maintenance and operation of road tunnel in: 23th International Symposium on Automation and Robotics in Construction ISARC, 2006, pp. 299-302, last $_{845}$ access date: $2 / 5 / 2019$.

775 URL https://www.iaarc.org/publications/proceedings_of

- the_23rd_isarc/state_of_the_art_and_future_prospect_ of_maintenance_and_operation_of_road_tunnel.html

[5] Y. Huang, W. He, K. Nahrstedt, W. C. Lee, Requirements and System ${ }_{850}$ Architecture Design Consideration for First Responder Systems, in: 2007 IEEE Conference on Technologies for Homeland Security, IEEE, 2007, pp. 39-44. doi:10.1109/THS.2007.370017

[6] W. Bergeson, S. Ernst, Tunnel Operations, Maintenance, Inspection, and Evaluation (TOMIE) Manual in: Federal Highway Administration, U.S $_{855}$ Department of Transportation, 2015, last access date: 2/5/2019.

785 URL https://www.fhwa.dot.gov/bridge/inspection/tunnel/ tomie/hif15005.pdf

[7] J. Victores, S. Martínez, A. Jardón, C. Balaguer, Robot-aided tunnel inspection and maintenance system by vision and proximity sensor in ${ }_{860}$ tegration, Automation in Construction 20 (5) (2011) 629-636. doi: $10.1016 / j$.autcon.2010.12.005

[8] R. Montero, J. Victores, S. Martínez, A. Jardón, C. Balaguer, Past, present and future of robotic tunnel inspection, Automation in Construction 59 (2015) 99-112. doi:10.1016/j.autcon.2015.02.003

[9] K. Nishijima, Y. Sun, R. K. Srivastava, H. Ogai, B. Bhattacharya, Advanced pipe inspection robot using rotating probe and image processing, in: 15th International Symposium on Artificial Life and Robotics, AROB' 10 2010, ISBN: 9784990288051.

[10] B. Zeller, L. Lombardi, P. Cyr, H. D. Mair, R. Ginzel, Remote Robotic Inspection of Irregular Surfaces on the Inner Diameter of the AECL NRU Reactor CINDE Journal 34 (1) (2013) 5-9, last access date: 2/5/2019. URL https://www.ndt.net/search/docs.php3?id=13142\& content=1

[11] E. Menendez, J. G. Victores, R. Montero, S. Martínez, C. Balaguer, Tunnel structural inspection and assessment using an autonomous robotic system, Automation in Construction 87 (2018) 117-126. doi:10.1016/j. autcon.2017.12.001

[12] D. Axinte, X. Dong, D. Palmer, A. Rushworth, et al., MiRoR-Miniaturized Robotic Systems for Holistic In-Situ Repair and Maintenance Works in Restrained and Hazardous Environments, IEEE/ASME Transactions on Mechatronics 23 (2) (2018) 978-981. doi :10.1109/TMECH. 2018. 2800285

[13] T. Rakha, A. Gorodetsky, Review of Unmanned Aerial System (UAS) applications in the built environment: Towards automated building inspection ${ }_{885}$ procedures using drones, Automation in Construction 93 (2018) 252-264. doi: 10.1016/j. autcon.2018.05.002

[14] P. Guruge, B. B. Kocer, E. Kayacan, A novel automatic UAV launcher design by using bluetooth low energy integrated electromagnetic releasing system, in: 2015 IEEE Region 10 Humanitarian Technology Confer- ${ }_{890}$ ence (R10-HTC), IEEE, 2015, pp. 1-4. doi:10.1109/R10-HTC.2015. 7391861

[15] D. Roca, S. Lagüela, L. Díaz-Vilariño, J. Armesto, P. Arias, Low-cost aerial unit for outdoor inspection of building façades, Automation in

(1) Construction 36 (2013) 128-135. doi:10.1016/j . autcon. 2013.08 020

825 [16] H. Zakeri, F. M. Nejad, A. Fahimifar, Rahbin: A quadcopter unmanned aerial vehicle based on a systematic image processing approach toward an automated asphalt pavement inspection, Automation in Construction 72 (2016) 211-235. doi:10.1016/j. autcon.2016.09.002
[17] X. Zhong, X. Peng, S. Yan, M. Shen, Y. Zhai, Assessment of the feasibility of detecting concrete cracks in images acquired by unmanned aerial vehicles, Automation in Construction 89 (2018) 49-57. doi: 10.1016/j.autcon.2018.01.005

[18] C.-H. Yang, M.-C. Wen, Y.-C. Chen, S.-C. Kang, An Optimized Unmanned Aerial System for Bridge Inspection, in: ISARC. Proceedings of the International Symposium on Automation and Robotics in Construction, Vol. 32 Vilnius Gediminas Technical University, Department of Construction Economics , 2015, pp. 1-6. doi:10.22260/ISARC2015/0084

[19] S. Dorafshan, M. Maguire, N. V. Hoffer, C. Coopmans, Challenges in bridge inspection using small unmanned aerial systems: Results and lessons learned, in: 2017 International Conference on Unmanned Aircraft Systems (ICUAS), IEEE, 2017, pp. 1722-1730. doi:10.1109/ ICUAS.2017.7991459

[20] S. Dorafshan, R. J. Thomas, M. Maguire, Fatigue Crack Detection Using Unmanned Aerial Systems in Fracture Critical Inspection of Steel Bridges, Journal of Bridge Engineering 23 (10) (2018) 04018078. doi:10.1061/ (ASCE) BE. 1943-5592.0001291

[21] I.-H. Kim, H. Jeon, S.-C. Baek, W.-H. Hong, H.-J. Jung, Application of Crack Identification Techniques for an Aging Concrete Bridge Inspection Using an Unmanned Aerial Vehicle, Sensors 18 (6) (2018) 1881. doi: $10.3390 / \mathrm{s} 18061881$

[22] S. Hiasa, E. Karaaslan, W. Shattenkirk, C. Mildner, F. N. Catbas, Bridge Inspection and Condition Assessment Using Image-Based Technologies with UAVs, in: Structures Congress 2018, pp. 217-228. doi:10.1061/ 9780784481332.020

[23] B. Lei, N. Wang, P. Xu, G. Song, New Crack Detection Method for Bridge Inspection Using UAV Incorporating Image Processing, Journal of Aerospace Engineering 31 (5) (2018) 04018058. doi:10.1061/(ASCE) AS.1943-5525.0000879

[24] A. Ellenberg, A. Kontsos, F. Moon, I. Bartoli, Bridge deck delamination identification from unmanned aerial vehicle infrared imagery, Automation in Construction 72 (2016) 155-165. doi:10.1016/j.autcon.2016 08.024

[25] J. Seo, L. Duque, J. Wacker, Drone-enabled bridge inspection methodology and application, Automation in Construction 94 (2018) 112-126. doi: 10.1016/j. autcon.2018.06.006

[26] T. Omar, M. L. Nehdi, Remote sensing of concrete bridge decks using unmanned aerial vehicle infrared thermography, Automation in Construction 83 (2017) 360-371. doi:10.1016/j . autcon.2017.06.024

[27] B. B. Kocer, T. Tjahjowidodo, G. S. G. Lee, Constrained Estimation-based Nonlinear Model Predictive Control for UAV-Elastic Tool Interaction, in: 2018 IEEE/ASME International Conference on Advanced Intelligent Mechatronics (AIM), IEEE, 2018, pp. 466-471. doi:10.1109/AIM 2018.8452262

[28] B. B. Kocer, T. Tjahjowidodo, G. G. L. Seet, Uav Push Recovery Operation by Symmetrical Control and Estimation in Receding Horizon, in: 2018 15th International Conference on Control, Automation, Robotics and Vision (ICARCV), IEEE, 2018, pp. 978-983. doi:10.1109/ICARCV 2018.8581186

[29] K. H. Petersen, N. Napp, R. Stuart-Smith, D. Rus, M. Kovac, A review of collective robotic construction, Science Robotics 4 (28). doi:10.1126/ scirobotics.aau8479

[30] S. Goessens, C. Mueller, P. Latteur, Feasibility study for drone-based masonry construction of real-scale structures, Automation in Construction 94 (2018) 458-480. doi:10.1016/j.autcon.2018.06.015

[31] P. Chermprayong, K. Zhang, F. Xiao, M. Kovac, An Integrated Delta Manipulator for Aerial Repair: A New Aerial Robotic System, IEEE Robotics \& Automation Magazine 26 (1) (2019) 54-66. doi:10.1109/ MRA.2018.2888911

[32] H. B. Khamseh, F. Janabi-Sharifi, A. Abdessameud, Aerial manipulationA literature survey, Robotics and Autonomous Systems 107 (2018) 221235. doi:10.1016/j.robot.2018.06.012

[33] F. Ruggiero, V. Lippiello, A. Ollero, Aerial Manipulation: A Literature Review, IEEE Robotics and Automation Letters 3 (3) (2018) 1957-1964. doi:10.1109/LRA.2018.2808541

[34] X. Ding, P. Guo, K. Xu, Y. Yu, A review of aerial manipulation of smallscale rotorcraft unmanned robotic systems, Chinese Journal of Aeronautics 32 (1) (2018) 200-214. doi:10.1016/j.cja.2018.05.012

[35] K. Alexis, C. Huerzeler, R. Siegwart, Hybrid modeling and control of a coaxial unmanned rotorcraft interacting with its environment through con- 
tact, in: 2013 IEEE International Conference on Robotics and Automation, IEEE, 2013, pp. 5417-5424. doi:10.1109/ICRA.2013.6631354

[36] S. Mizutani, Y. Okada, C. J. Salaan, T. Ishii, K. Ohno, S. Tadokoro, Proposal and experimental validation of a design strategy for a UAV with a passive rotating spherical shell, in: 2015 IEEE/RSJ International975 Conference on Intelligent Robots and Systems (IROS), IEEE, 2015, pp. 1271-1278. doi:10.1109/IROS.2015.7353532

[37] A. Ollero, G. Heredia, A. Franchi, G. Antonelli, K. Kondak, A. Sanfeliu, A. Viguria, J. R. Martinez-de Dios, F. Pierri, J. Cortes, A. SantamariaNavarro, M. A. Trujillo Soto, R. Balachandran, J. Andrade-Cetto, A. Ro-98 driguez, The AEROARMS Project: Aerial Robots with Advanced Manipulation Capabilities for Inspection and Maintenance, IEEE Robotics Automation Magazine 25 (4) (2018) 12-23. doi:10.1109/MRA.2018 2852789

[38] M. Tognon, H. T. Chvez, E. Gasparin, Q. Sabl, D. Bicego, A. Mallet,985 M. Lany, G. Santi, B. Revaz, J. Cortes, A. Franchi, A Truly Redundant Aerial Manipulator System with Application to Push-and-Slide Inspection in Industrial Plants, IEEE Robotics and Automation Letters 4 (2) (2019) 1846-1851. doi:10.1109/LRA.2019.2895880

[39] K. Yanagimura, K. Ohno, Y. Okada, E. Takeuchi, S. Tadokoro, Hovering of 990 MAV by using magnetic adhesion and winch mechanisms, in: 2014 IEEE International Conference on Robotics and Automation (ICRA), IEEE, 2014, pp. 6250-6257. doi:10.1109/ICRA .2014.6907781

[40] Q. Delamare, P. R. Giordano, A. Franchi, Toward Aerial Physical Locomotion: The Contact-Fly-Contact Problem, IEEE Robotics and Automation995 Letters 3 (3) (2018) 1514-1521. doi:10.1109/LRA. 2018.2800798

[41] K. Takeuchi, A. Masuda, S. Akahori, Y. Higashi, N. Miura, A close inspection and vibration sensing aerial robot for steel structures with an EPM-based landing device, in: Nondestructive Characterization and Monitoring of Advanced Materials, Aerospace, and Civil Infrastructureooo 2017, Vol. 10169, International Society for Optics and Photonics, 2017, p. 101692U. doi: $10.1117 / 12.2260386$

[42] P. J. Sanchez-Cuevas, P. Ramon-Soria, B. Arrue, A. Ollero, G. Heredia, Robotic System for Inspection by Contact of Bridge Beams Using UAVs, Sensors 19 (2) (2019) 305. doi:10.3390/s19020305

[43] A. E. Jimenez-Cano, G. Heredia, A. Ollero, Aerial manipulator with a compliant arm for bridge inspection, in: 2017 International Conference on Unmanned Aircraft Systems (ICUAS), 2017, pp. 1217-1222. doi: 10.1109/ICUAS. 2017.7991458

[44] A. E. Jimenez-Cano, J. Braga, G. Heredia, A. Ollero, Aerial manipulatoro10 for structure inspection by contact from the underside, in: 2015 IEEE/RSJ International Conference on Intelligent Robots and Systems (IROS), 2015, pp. 1879-1884. doi:10.1109/IROS.2015.7353623

[45] R. Mattar, R. Kalai, Development of a Wall-Sticking Drone for NonDestructive Ultrasonic and Corrosion Testing, Drones 2 (1) (2018) 8015 doi:10.3390/drones2010008

[46] T. Ikeda, S. Yasui, M. Fujihara, K. Ohara, S. Ashizawa, A. Ichikawa, A. Okino, T. Oomichi, T. Fukuda, Wall contact by octo-rotor UAV with one DoF manipulator for bridge inspection, in: 2017 IEEE/RSJ International Conference on Intelligent Robots and Systems (IROS), IEEE, 2017, pp.20 5122-5127. doi:10.1109/IROS.2017.8206398

[47] T. Ikeda, S. Yasui, S. Minamiyama, K. Ohara, S. Ashizawa, A. Ichikawa, A. Okino, T. Oomichi, T. Fukuda, Stable impact and contact force control by UAV for inspection of floor slab of bridge, Advanced Robotics 32 (19) (2018) 1061-1076. doi:10.1080/01691864.2018.1525075

[48] K. Bodie, M. Brunner, M. Pantic, S. Walser, P. Pfändler, U. Angst, R. Siegwart, J. Nieto, An Omnidirectional Aerial Manipulation Platform for Contact-Based Inspection arXiv preprint arXiv:1905.03502 last access date: $2 / 5 / 2019$. URL https://arxiv.org/abs/1905.03502

[49] K. Alexis, G. Darivianakis, M. Burri, R. Siegwart, Aerial robotic contactbased inspection: planning and control, Autonomous Robots 40 (4) (2016) 631-655. doi:10.1007/s10514-015-9485-5

[50] G. Garimella, M. Kobilarov, Towards model-predictive control for aerial pick-and-place, in: 2015 IEEE International Conference on Robotics ando3 Automation (ICRA), IEEE, 2015, pp. 4692-4697. doi:10.1109/ICRA 2015.7139850

[51] D. Lunni, A. Santamaria-Navarro, R. Rossi, P. Rocco, L. Bascetta, J. Andrade-Cetto, Nonlinear model predictive control for aerial manipulation, in: 2017 International Conference on Unmanned Aircraft Systemso40 (ICUAS), 2017, pp. 87-93. doi:10.1109/ICUAS. 2017.7991347
[52] N. Metni, T. Hamel, A UAV for bridge inspection: Visual servoing control law with orientation limits, Automation in Construction 17 (1) (2007) 3-10. doi:10.1016/j.autcon.2006.12.010

[53] B. B. Kocer, T. Tjahjowidodo, G. G. L. Seet, Centralized predictive ceiling interaction control of quadrotor VTOL UAV, Aerospace Science and Technology 76 (2018) 455 - 465. doi:10.1016/j . ast. 2018.02.020

[54] B. B. Kocer, T. Tjahjowidodo, G. G. L. Seet, Model predictive UAV-tool interaction control enhanced by external forces, Mechatronics 58 (2019) 47 - 57. doi:10.1016/j.mechatronics. 2019.01.004

[55] B. B. Kocer, V. E. Omurlu, E. Akdogan, C. S. Tufekci, Development of a MEMs-based IMU Unit, in: 2013 6th International Conference on Recent Advances in Space Technologies (RAST), 2013, pp. 389-393. doi:10.1109/RAST.2013.6581237

[56] M. Vukov, S. Gros, G. Horn, G. Frison, K. Geebelen, J. B. Jørgensen, J. Swevers, M. Diehl, Real-time nonlinear MPC and MHE for a large-scale mechatronic application, Control Engineering Practice 45 (2015) 64-78. doi:10.1016/j.conengprac. 2015.08.012

[57] M. Diehl, H. J. Ferreau, N. Haverbeke, Efficient Numerical Methods for Nonlinear MPC and Moving Horizon Estimation, in: Nonlinear Model Predictive Control, Springer, 2009, pp. 391-417. doi:10.1007/ 978-3-642-01094-1_32

[58] P. Kuhl, M. Diehl, T. Kraus, J. P. Schloder, H. G. Bock, A real-time algorithm for moving horizon state and parameter estimation, Computers \& Chemical Engineering 35 (1) (2011) $71-83$. doi:10.1016/j compchemeng.2010.07.012

[59] D. Limon, J. Calliess, J. Maciejowski, Learning-based Nonlinear Model Predictive Control, IFAC-PapersOnLine 50 (1) (2017) 7769 - 7776, 20th IFAC World Congress. doi:10.1016/j.ifacol.2017.08.1050

[60] U. Eren, A. Prach, B. B. Koçer, S. V. Raković, E. Kayacan, B. Açıkmeşe, Model Predictive Control in Aerospace Systems: Current State and Opportunities, Journal of Guidance, Control, and Dynamics 40 (7) (2017) 1541-1566. doi:10.2514/1.G002507

[61] B. B. Kocer, G. G. L. Seet, T. Tjahjowidodo, Nonlinear Predictive UAVElastic Tool Interaction Control in Real-time, in: 2018 IEEE/ASME International Conference on Advanced Intelligent Mechatronics (AIM), IEEE, 2018, pp. 472-477. doi:10.1109/AIM. 2018.8452328

[62] K. Bekiroglu, C. Lagoa, S. A. Murphy, S. T. Lanza, Control Engineering Methods for the Design of Robust Behavioral treatments, IEEE Transactions on Control Systems Technology 25 (3) (2017) 979-990. doi:10.1109/TCST.2016.2580661

[63] D. Q. Mayne, J. B. Rawlings, C. V. Rao, P. O. Scokaert, Constrained model predictive control: Stability and optimality, Automatica 36 (6) (2000) 789-814. doi:10.1016/S0005-1098(99)00214-9

[64] N. Imanberdiyev, E. Kayacan, A Fast Learning Control Strategy for Unmanned Aerial Manipulators, Journal of Intelligent \& Robotic Systems (2018) 1-20doi:10.1007/s10846-018-0884-7

[65] J. F. Fisac, A. K. Akametalu, M. N. Zeilinger, S. Kaynama, J. Gillula, C. J. Tomlin, A General Safety Framework for Learning-Based Control in Uncertain Robotic Systems, IEEE Transactions on Automatic Control (2018) 1-1doi:10.1109/TAC.2018.2876389

[66] W. Hu, E. F. Camacho, L. Xie, Output Feedback Control Based on State and Disturbance Estimation arXiv preprint arXiv:1801.06058 last access date: $2 / 5 / 2019$.

URL https://arxiv.org/abs/1801.06058

[67] C. J. Ostafew, A. P. Schoellig, T. D. Barfoot, J. Collier, Learning-based Nonlinear Model Predictive Control to Improve Vision-based Mobile Robot Path Tracking, Journal of Field Robotics 33 (1) (2016) 133-152. doi: $10.1002 / \mathrm{rob} .21587$

[68] M. Mehndiratta, E. Camci, E. Kayacan, Automated Tuning of Nonlinear Model Predictive Controller by Reinforcement Learning, in: 2018 IEEE/RSJ International Conference on Intelligent Robots and Systems (IROS), IEEE, 2018, pp. 3016-3021. doi:10.1109/IROS.2018 8594350

[69] B. Houska, H. J. Ferreau, M. Diehl, ACADO toolkit-An open-source framework for automatic control and dynamic optimization, Optimal Control Applications and Methods 32 (3) (2011) 298-312. doi:10.1002/ oca.939

[70] B. Houska, H. J. Ferreau, M. Diehl, An auto-generated real-time iteration algorithm for nonlinear MPC in the microsecond range, Automatica 47 (10) (2011) $2279-2285$. doi:10.1016/j . automatica. 2011.08.020

[71] M. Diehl, H. G. Bock, H. Diedam, P.-B. Wieber, Fast Direct Multiple 
Shooting Algorithms for Optimal Robot Control, in: Fast Motions in Biomechanics and Robotics, Springer, 2006, pp. 65-93. doi:10.1007/ 978-3-540-36119-0_4

[72] H. J. Ferreau, H. G. Bock, M. Diehl, An online active set strategy to overcome the limitations of explicit MPC, International Journal of Robust and Nonlinear Control 18 (8) (2008) 816-830. doi:10.1002/rnc.1251

[73] B. B. Kocer, V. Kumtepeli, T. Tjahjowidodo, M. Pratama, A. Tripathi, G. S. G. Lee, Y. Wang, Uav Control in Close Proximities-Ceiling Effect $1050 \quad$ on Battery Lifetime arXiv preprint arXiv:1812.11707 last access date: 2/5/2019.

URL https://arxiv.org/abs/1812.11707

[74] V. Kumtepeli, Y. Zhao, M. Naumann, A. Tripathi, Y. Wang, A. Jossen, H. C. Hesse, Design and analysis of an aging-aware energy management 1055 system for islanded grids using mixed-integer quadratic programming, 1. International Journal of Energy Research (2019) 1-18doi:10.1002/er 4512 